\title{
Current Methodological Pitfalls and Caveats in the Assessment of Exercise-Induced Changes in Peripheral Brain-Derived Neurotrophic Factor: How Result Reproducibility Can Be Improved
}

\author{
Chiara Nicolini and Aimee J. Nelson* \\ Department of Kinesiology, McMaster University, Hamilton, ON, Canada
}

OPEN ACCESS

Edited by:

Wei-Peng Teo,

Nanyang Technological

University, Singapore

Reviewed by:

Jason L. Neva,

University of Montreal, Canada

Alicia M. Goodwill,

Nanyang Technological

University, Singapore

${ }^{*}$ Correspondence:

Aimee J. Nelson

nelsonaj@mcmaster.ca

Specialty section: This article was submitted to Augmented and Synthetic

Neuroergonomics,

a section of the journal

Frontiers in Neuroergonomics

Received: 09 March 2021 Accepted: 04 May 2021

Published: 28 May 2021

Citation:

Nicolini C and Nelson AJ (2021)

Current Methodological Pitfalls and

Caveats in the Assessment of

Exercise-Induced Changes in

Peripheral Brain-Derived Neurotrophic

Factor: How Result Reproducibility

Can Be Improved.

Front. Neuroergon. 2:678541.

doi: 10.3389/fnrgo.2021.678541
Neural mechanisms, such as enhanced neuroplasticity within the motor system, underpin exercise-induced motor improvements. Being a key mediator of motor plasticity, brain-derived neurotrophic factor (BDNF) is likely to play an important role in mediating exercise positive effects on motor function. Difficulties in assessing brain BDNF levels in humans have drawn attention to quantification of blood BDNF and raise the question of whether peripheral BDNF contributes to exercise-related motor improvements. Methodological and non-methodological factors influence measurements of blood BDNF introducing a substantial variability that complicates result interpretation and leads to inconsistencies among studies. Here, we discuss methodology-related issues and approaches emerging from current findings to reduce variability and increase result reproducibility.

Keywords: exercise, BDNF, neuroplasticity, mobility, motor cortex, serum, plasma, ELISA

\section{INTRODUCTION}

A growing body of evidence shows that exercise helps attenuate disease-related motor impairments (Stein, 2004; Marigold et al., 2005; Crizzle and Newhouse, 2006; Herman et al., 2007; Gobbi et al., 2009; Quaney et al., 2009; Ridgel et al., 2009; Cooke et al., 2010; Hauer et al., 2012; Vreugdenhil et al., 2012; Gomes de Melo Coelho et al., 2013b; Pitkälä et al., 2013; van der Kolk and King, 2013; Schwenk et al., 2014a,b; Duchesne et al., 2015; Dennett et al., 2016; Cugusi et al., 2019; Gretebeck et al., 2019; Linder et al., 2019) and maintain motor function in aging adults (Rikli and Edwards, 1991; Buckwalter, 1997; Campbell et al., 1999; Visser et al., 2002; Means et al., 2005; Pahor et al., 2014; Bolandzadeh et al., 2015; Brach et al., 2017; Hsu et al., 2017a,b; Hübner et al., 2018). Age- and disease-associated motor impairments include reduced balance, motor control, gait speed and stride length, altered rhythm, rigidity, and slow movements and lead to a decline in physical functioning and mobility, and consequently to falls and fall-related injuries, which result in a loss of independence, morbidity, and mortality (Overstall et al., 1977; Winter et al., 1990; Tinetti and Williams, 1998; Sterling et al., 2001; Jørgensen et al., 2002; Grimbergen et al., 2004; Todd and Skelton, 2004; Weerdesteyn et al., 2008; Ioannidis et al., 2009; Blankevoort et al., 2010; Deandrea et al., 2010; Tinetti and Kumar, 2010; Fasano et al., 2017; Lach et al., 2017; Xu et al., 2018; Osoba et al., 2019; Zhang et al., 2019). Since exercise improves mobility, gait speed 
and rhythmicity, stride length, postural reflexes, balance, and motor control in the elderly, stroke survivors, and individuals with Parkinson's, Alzheimer's, or dementia (Marigold et al., 2005; Crizzle and Newhouse, 2006; Herman et al., 2007; Goodwin et al., 2008; Gobbi et al., 2009; Quaney et al., 2009; Blankevoort et al., 2010; Brienesse and Emerson, 2013; van der Kolk and King, 2013; Schwenk et al., 2014b; Mehrholz et al., 2015), it appears effective at prolonging the ability to perform daily activities and at reducing injuries, morbidity, and mortality related to falls. However, our understanding of how exercise improves mobility, balance, motor control, and gait parameters such as speed, rhythmicity, and stride length needs to be expanded (Figure 1). It is now widely acknowledged that exercise benefits mobility not just by improving physiological function, such as muscle strength and balance (Robertson et al., 2002; LiuAmbrose et al., 2008, 2013), but also through neural mechanisms (e.g., enhanced neuroplasticity, maintenance of white and gray matter integrity and volume in motor brain areas) (Shepherd, 2001; Colcombe et al., 2003, 2006; Forrester et al., 2008; Quaney et al., 2009; Petzinger et al., 2010, 2013; Mang et al., 2013; Perrey, 2013; Duchesne et al., 2016; Hirsch et al., 2016; Nepveu et al., 2017; Steib et al., 2018). Nevertheless, studies providing direct evidence are few (Fisher et al., 2008; Skriver et al., 2014; Bolandzadeh et al., 2015; Ostadan et al., 2016; Hsu et al., 2017a,b; Dal Maso et al., 2018; Hübner et al., 2018; Lehmann et al., 2020). Specifically, Hsu et al. (2017a,b) showed that exerciseinduced maintenance of functional connectivity within frontoparietal networks, which are involved in motor planning and execution, was linked to improved mobility in elderly subjects with mild subcortical ischemic vascular cognitive impairment. Bolandzadeh et al. (2015) found that exercise-related reduction in the progression of white matter lesions was associated with gait speed maintenance in older women. Further, Fisher et al. (2008) and Hübner et al. (2018) reported that exercise-induced improvements in gait parameters (i.e., speed, step and stride length, hip and ankle joint excursion) and fine motor control (as measured by a precision grip force modulation task) were accompanied with primary motor cortex excitability changes (i.e., longer cortical silent period) in Parkinson's patients and enhanced frontal and sensorimotor cortex activity (i.e., decreases in EEG task-related power in the beta band, 13-30 Hz) in healthy, elderly subjects, respectively. Last, greater motor skill acquisition and retention as well as learning of a new motor task have been shown to be associated with larger changes in neural activity, corticospinal excitability, $\mathrm{GABA}_{\mathrm{A}}$-mediated inhibition (i.e., short-interval intracortical inhibition, SICI), white matter microstructure, and brain-derived neurotrophic factor (BNDF) levels in young, healthy adults following exercise (Skriver et al., 2014; Ostadan et al., 2016; Stavrinos and Coxon, 2017; Dal Maso et al., 2018; Lehmann et al., 2020). Of note, the ability of exercise to promote motor skill learning and retention has important implications during rehabilitation, for example poststroke, for the recovery of motor disabilities which hinder independent living (Mang et al., 2013). Promisingly, Quaney et al. (2009) reported that exercise lead to improvements in motor learning which in turn, translated into improved fine motor control (i.e., greater predictive force modulation to grasp and lift an object) in chronic stroke survivors. Despite these promising findings supporting the notion that neural substrates (e.g., enhanced neuroplasticity within motor networks promoting motor learning) mediate exercise positive effects on mobility, gait, balance, and motor control, the mechanistic links between exercise and motor improvements largely remains to be unraveled (Figure 1). Indeed, as exercise-induced structural and functional brain changes as well as motor outcomes have been mainly assessed in separate studies, it is pivotal for shedding light onto the neural correlates of exercise-induced motor improvements that these different levels of analysis (i.e., systemic, cellular, molecular, and behavioral) are carried out within the same study in future research.

Approaches used to garner evidence of exercise-linked systemic, cellular, and molecular changes include quantification of molecular markers (e.g., BDNF, osteocalcin, and irisin) in blood using enzyme-linked immunosorbent assays (ELISAs), assessment of corticospinal excitability using single-pulse transcranial magnetic stimulation (TMS), evaluation of GABAergic [i.e., short-interval intracortical inhibition, SICI, and long-interval intracortical inhibition, LICI, reflecting $\mathrm{GABA}_{\mathrm{A}}$-mediated inhibition and $\mathrm{GABA}_{\mathrm{B}}$-mediated inhibition, respectively (Rossini et al., 2015; Ziemann et al., 2015)] and glutamatergic (i.e., intracortical facilitation, ICF, and shortinterval intracortical facilitation, SICF) motor circuits via paired-pulse TMS paradigms, and measurement of white matter (WM) tract integrity and neurometabolite concentrations [e.g., inhibitory neurotransmitter $\gamma$-aminobutyric acid (GABA) and excitatory neurotransmitter glutamate] with magnetic resonance techniques such as diffusion tensor imaging (DTI) and magnetic resonance spectroscopy (MRS). Here, we focus on brain-derived neurotrophic factor, likely a key mediator of the positive effects of exercise on mobility, gait, balance, and motor control by promoting neuroplasticity within motor brain circuits which, in turn, facilitates motor learning (Figure 2). We discuss limitations and future avenues for the investigation of BDNF contribution to exercise-related motor outcomes. Understanding the mechanisms through which aerobic exercise promotes brain plasticity and ultimately leads to motor benefits is critical for the design of exercise protocols effective in the prevention, delay, attenuation, and recovery of age- and disease-related motor impairments.

\section{BRAIN-DERIVED NEUROTROPHIC FACTOR}

The molecular mediators of exercise-induced brain changes, such as enhanced neuroplasticity, which by facilitating motor learning likely contributes to exercise-related motor improvements (i.e., mobility, gait, balance, and motor control), are still largely unknown. Molecular markers that have been identified as likely candidates include the neurotrophin brain-derived neurotrophic factor (BDNF), the growth factor insulin-like growth factor 1 (IGF-1), the bone-derived hormone osteocalcin (OCN), and lastly myokines cathepsin $\mathrm{B}$ and irisin. In this review, special attention is paid to BDNF, a member of the neurotrophin family 


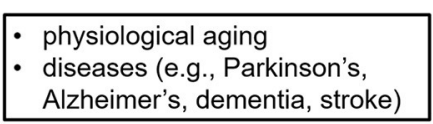

diseases (e.g., Parkinson's,

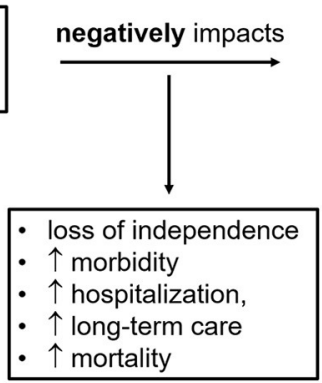

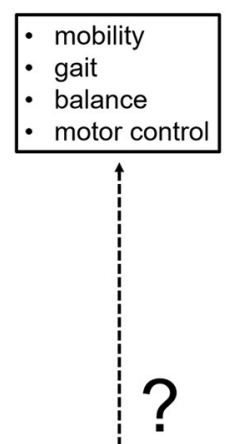

positively impacts

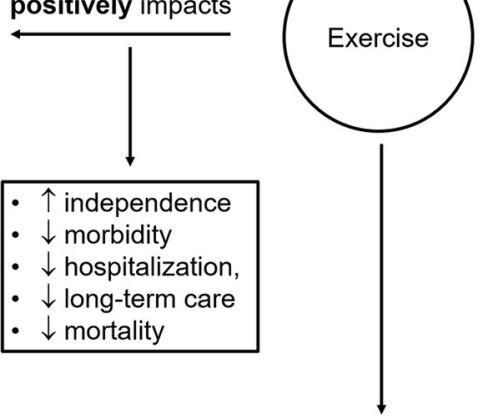

neural mechanisms:

systemic, cellular, and molecular changes

(e.g., $\uparrow$ functional connectivity,

$\uparrow \mathrm{GM}$ volume, $\uparrow \mathrm{WM}$ integrity, $\uparrow \mathrm{CSE}$, $\downarrow \mathrm{SICl}, \uparrow \mathrm{BDNF})$

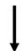

optimal environment for neuroplasticity

in cortico-motor networks

motor learning

FIGURE 1 | Effects of age, illness, and exercise on motor outcomes and brain mechanisms underpinning exercise-related motor benefits. BDNF, brain-derived neurotrophic factor; CSE, corticospinal excitability; GM, gray matter; SICl, short-interval intracortical inhibition; WM, white matter; ?, knowledge gaps to be addressed and filled by future research.

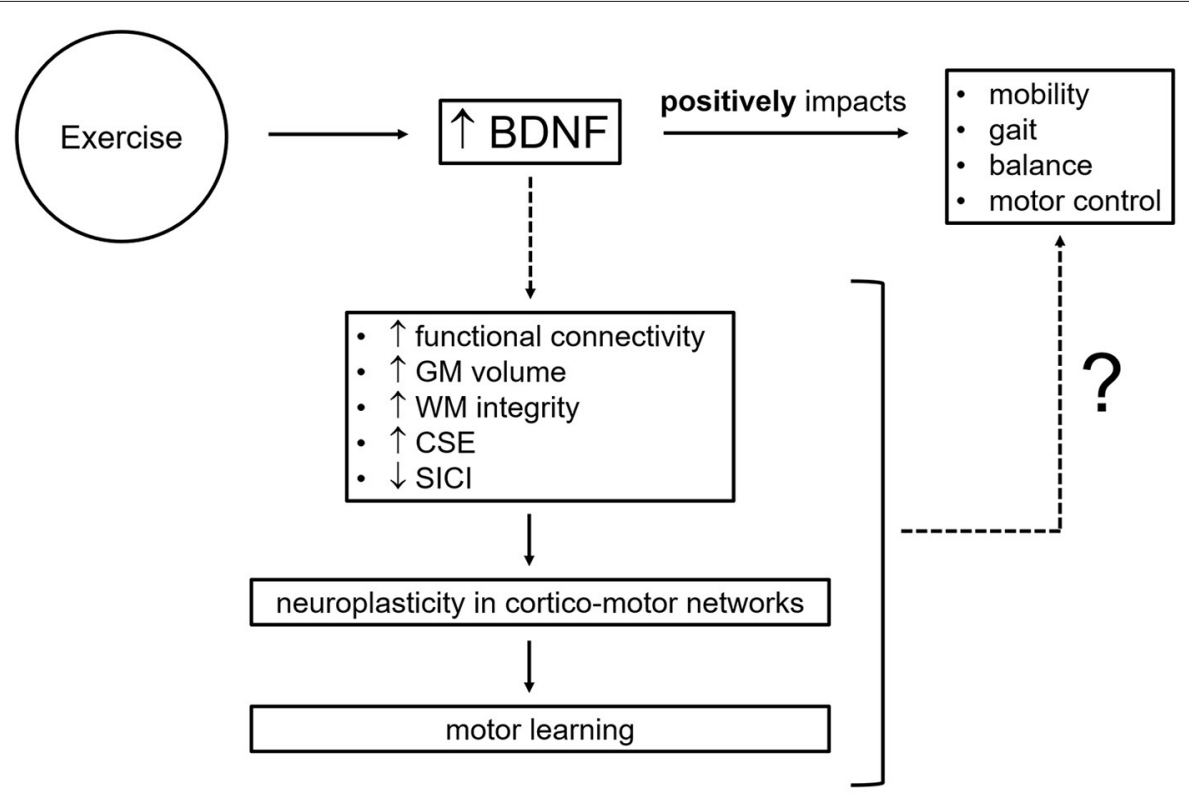

FIGURE 2 | Potential neural mechanisms by which brain-derived neurotrophic factor mediates exercise-related motor improvements. BDNF, brain-derived neurotrophic factor; CSE, corticospinal excitability; GM, gray matter; SICl, short-interval intracortical inhibition; WM, white matter; ?, knowledge gaps to be addressed and filled by future research. 
which includes nerve growth factor (NGF), neurotrophin 3, and neurotrophin 4/5 (Barde, 1994; Lewin and Barde, 1996; Hallböök, 1999). Since its discovery in 1982 (Barde et al., 1982), BDNF has been demonstrated to be essential for normal brain development and adult brain function with alterations in its levels accompanying neurological and psychiatric disorders (McAllister et al., 1995; Huang and Reichardt, 2001; McAllister, 2002; Tyler et al., 2002; Binder and Scharfman, 2004; Bramham and Messaoudi, 2005; Kuipers and Bramham, 2006; Brunoni et al., 2008; Chapleau et al., 2009; Fahnestock, 2011; Fernandes et al., 2011; Green et al., 2011; Carlino et al., 2013; Park and Poo, 2013; Molendijk et al., 2014; Fahnestock and Nicolini, 2015; Hempstead, 2015; Armeanu et al., 2017; Illarioshkin et al., 2018; Mohammadi et al., 2018; Numakawa et al., 2018; Di Carlo et al., 2019; Huang et al., 2019; Lima Giacobbo et al., 2019; Ng et al., 2019). BDNF is synthesized as a $32-\mathrm{kDa}$ precursor, called proBDNF, which is subsequently cleaved, either intracellularly (e.g., by serine protease furin and prohormone convertases) or extracellularly (e.g., by matrix metalloproteases or serine protease plasmin), into a $14-\mathrm{kDa}$ mature form (Seidah et al., 1996; Lee et al., 2001; Mowla et al., 2001; Pang et al., 2004, 2016). ProBDNF is not an inactive precursor but has distinct and opposite functions from mature BDNF ( $\mathrm{Lu}$ et al., 2005). Specifically, proBDNF reduces neuronal survival, neurite growth, and dendritic spine formation and induces neuronal apoptosis and long-term depression via p75 neurotrophin receptor (p75NTR) (Teng et al., 2005; Woo et al., 2005; Koshimizu et al., 2009). Mature BDNF promotes neuronal differentiation and survival, neurite growth, neural circuit formation, function, and maintenance, synaptogenesis, and synaptic plasticity, both during development and throughout adulthood, via tyrosine kinase receptor tropomyosin-related kinase B (TrkB) (McAllister et al., 1999; Schinder and Poo, 2000; Huang and Reichardt, 2001; Poo, 2001; McAllister, 2002; Binder and Scharfman, 2004; Waterhouse and Xu, 2009; Park and Poo, 2013; Leal et al., 2014, 2017; Lu et al., 2014; Gibon and Barker, 2017; Kowiański et al., 2018). Through a different cleavage site, proBDNF can be converted into a $28-\mathrm{kDa}$ protein (truncated BDNF) (Seidah et al., 1999; Mowla et al., 2001), which is not an intermediate product in the proteolytic processing of proBDNF into mature BDNF, but whose biological activities are still unknown. Of note, an altered balance of the three BDNF proteolytic isoforms (i.e., pro, truncated, mature) has been observed in patients with schizophrenia and idiopathic autism (Carlino et al., 2011; Garcia et al., 2012), suggesting that all three isoforms play important roles for normal brain function.

\section{Brain-Derived Neurotrophic Factor and Exercise}

A number of studies have shown that exercise elevates peripheral BDNF concentrations (Gold et al., 2003; Ferris et al., 2007; Goekint et al., 2008; Tang et al., 2008; Zoladz et al., 2008; Rasmussen et al., 2009; Knaepen et al., 2010; Seifert et al., 2010; Yarrow et al., 2010; Zoladz and Pilc, 2010; Bos et al., 2011; Griffin et al., 2011; Rojas Vega et al., 2011; Cho et al., 2012; Heyman et al., 2012; Schmidt-Kassow et al., 2012; Gomes de Melo
Coelho et al., 2013a, 2014; Pereira et al., 2013; Schmolesky et al., 2013; Huang et al., 2014; Leckie et al., 2014; Mang et al., 2014; Skriver et al., 2014; Saucedo Marquez et al., 2015; Szuhany et al., 2015; Dinoff et al., 2017; Helm et al., 2017; Mackay et al., 2017; Marinus et al., 2019; de Azevedo et al., 2020; Nicolini et al., 2020). Specifically, acute endurance exercise protocols encompassing graded maximal, moderate-to-high-intensity continuous $(\sim 60-$ $80 \%$ of age-predicted maximal heart rate or heart rate reserve; $\sim 55-75 \%$ of maximal power output as measured with a maximal oxygen uptake test), and high-intensity intermittent (90\% of maximal power output) exercise result in a transient increase in blood BDNF in both healthy and clinical populations (Gold et al., 2003; Ferris et al., 2007; Winter et al., 2007; Goekint et al., 2008; Tang et al., 2008; Gustafsson et al., 2009; Laske et al., 2010; Bos et al., 2011; Cho et al., 2012; Heyman et al., 2012; Schmolesky et al., 2013; Mang et al., 2014; Skriver et al., 2014; Saucedo Marquez et al., 2015; Nicolini et al., 2020). Contrary to acute endurance exercise protocols, endurance exercise training programs have yielded inconsistent results. Indeed, while most studies have found that exercise training does not result in permanently elevated basal, peripheral BDNF levels (Schulz et al., 2004; Schiffer et al., 2009; Baker et al., 2010; Erickson et al., 2011; Ruscheweyh et al., 2011; Voss et al., 2013a; Maass et al., 2016; Goldfield et al., 2018, 2019; Gourgouvelis et al., 2018; Nicolini et al., 2019), Zoladz et al. (2008) and Jeon and Ha (2017) determined that a five-week, moderate- and twelveweek, moderate-to-high-intensity, endurance training increased BDNF in physically active, male subjects and adolescent males, respectively. Zoladz et al. (2008) also showed that athletes had higher basal BDNF concentrations than untrained individuals. Leckie et al. (2014) reported that moderate-intensity walking over a year lead to enhanced BDNF levels, but only in individuals older than 65 years of age. Further, Heisz et al. (2017), albeit finding no group differences in BDNF levels between healthy, low-active subjects who underwent training and those who did not, observed that high responders to exercise (i.e., individuals with greater cardiorespiratory fitness gains) had larger BDNF increases following 6 weeks of high-intensity interval training. Lastly, Seifert et al. (2010) found that 3 months of endurance training increased basal, internal jugular venous BDNF in sedentary, healthy males, pointing to an elevated release of BDNF from the brain following exercise training. Based on these findings, it appears that (1) intense and prolonged training (i.e., athletes) lastingly increases basal, peripheral BDNF (Zoladz et al., 2008); that (2) moderate-intensity training might be sufficient to increase basal, peripheral BDNF in physically active (Zoladz et al., 2008) and older (Leckie et al., 2014) individuals but not in low-active individuals (Gourgouvelis et al., 2018); that (3) to enhance basal, peripheral BDNF levels in low-active subjects, the duration of training should be longer than 6 weeks (Heisz et al., 2017; Nicolini et al., 2019); that (4) even though exercise training might not result in an increase in basal, peripheral BDNF, it facilitates increases in blood BDNF after an acute exercise bout (i.e., BDNF increase following a single exercise session is greater after a period of training compared to BDNF increase after a single exercise session prior to training) (Zoladz et al., 2008; Bansi et al., 2013; Szuhany et al., 2015); that (5) training augments the 
release of BDNF from the brain, although this increase might not be sufficiently large to be detected in peripheral, venous blood collected from the arm (e.g., cubital vein) (Schiffer et al., 2009; Erickson et al., 2011; Ruscheweyh et al., 2011; Voss et al., 2013b; Maass et al., 2016; Heisz et al., 2017; Gourgouvelis et al., 2018; Nicolini et al., 2019). Of note, in healthy individuals, exercise intensity influences the magnitude of BDNF increase, with high-intensity exercise being more effective than low-tomoderate-intensity exercise in elevating BDNF levels (Ferris et al., 2007; Winter et al., 2007; Schmidt-Kassow et al., 2012; Schmolesky et al., 2013; Saucedo Marquez et al., 2015; Enette et al., 2017; Jeon and Ha, 2017; Antunes et al., 2020). Conversely, in clinical populations, even low-to-moderate intensity exercise enhances blood BDNF (Gold et al., 2003; Gustafsson et al., 2009; Laske et al., 2010). Findings from studies investigating whether resistance exercise elevates peripheral BDNF, acutely (i.e., after a single session) or lastingly (i.e., following a training program), are mixed. Goekint et al. (2010) and Correia et al. (2010) found that acute resistance exercise was not effective in elevating peripheral BDNF in healthy subjects, while Yarrow et al. (2010) reported a significant increase in peripheral BDNF following a single session of resistance exercise in a similar cohort. More recently, Marston et al. (2017) also observed that acute resistance exercise transiently elevated blood BDNF levels in healthy subjects. Notably, these authors, however, found that the increase in BDNF was significant only in the resistanceexercise-to-fatigue (i.e., hypertrophy) group involving three sets of ten repetitions with a 60-s recovery between each set (Marston et al., 2017), suggesting that similar to acute endurance exercise, the effect of acute resistance exercise is intensity dependent. Lastly, based on the evidence garnered thus far, resistance training appears to be ineffective in augmenting basal, peripheral BDNF. Specifically, Schiffer et al. (2009) and Goekint et al. (2010) reported no changes in basal, peripheral BDNF levels following resistance training (12 vs. 10 weeks) in healthy individuals. Further, Levinger et al. (2008) and Goldfield et al. (2018, 2019) observed similar results in middle-aged subjects with high or low metabolic risk factors and obese and overweight adolescents, respectively. Nonetheless, despite being unable to elevate basal, peripheral BDNF concentrations, resistance training similar to endurance training (Zoladz et al., 2008; Bansi et al., 2013; Szuhany et al., 2015) leads to a robust increase in peripheral BDNF following an acute bout of resistance exercise (i.e., primes BDNF response to acute resistance exercise) (Yarrow et al., 2010).

$\mathrm{BDNF}$ is a well-established key regulator of synaptic plasticity (Bramham and Messaoudi, 2005; Kleim et al., 2006; Kuipers and Bramham, 2006; Bekinschtein et al., 2008; Waterhouse and Xu, 2009; Fritsch et al., 2010; Yoshii and Constantine-Paton, 2010; Lu et al., 2014; Gibon and Barker, 2017; Leal et al., 2017; Kowiański et al., 2018), a neural substrate of cognitive function and motor behavior (Rioult-Pedotti et al., 2000; Muellbacher et al., 2002; Doyon and Benali, 2005; Monfils et al., 2005; McConnell et al., 2009; Dayan and Cohen, 2011; Cantarero et al., 2013). As such, it is likely that exercise-induced upregulation of BDNF contributes to enhanced plasticity within the motor system (Gómez-Pinilla et al., 2002), which, in turn, facilitates motor learning and translates into motor improvements such as increased fine motor control (Quaney et al., 2009) (Figure 2). In mice, long-term exercise increases BDNF levels in brain motor areas, such as the primary motor cortex and cerebellum, and improves motor coordination (Inoue et al., 2018). However, in humans, it remains to be determined whether increases in peripheral BDNF following exercise are mechanistically linked to exercise-induced increases in motor plasticity and ultimately to exercise-induced motor gains (e.g., improved mobility, gait, balance, and fine motor control). To date, few studies, all in healthy individuals, have investigated whether elevated blood BDNF is associated with improved motor learning following acute exercise (Mang et al., 2014; Skriver et al., 2014; Helm et al., 2017; Baird et al., 2018). Only Skriver et al. (2014) found a positive correlation. Of note, Baird et al. (2018) did not observe a significant rise in plasma BDNF concentrations following exercise. Lastly, an association between increased serum BDNF and increased motor plasticity (i.e., enhanced TMS-probed corticospinal excitability) after a single bout of exercise has yet to be found (Mang et al., 2014; Nicolini et al., 2020). To determine BDNF contribution to exercise-induced motor improvements, it is thus important that future studies investigate further whether a correlation between exercise-induced changes in BDNF and exercise-induced changes in motor outcomes, encompassing mobility, gait, balance, and motor control, exists following both acute exercise and training in healthy and clinical populations. In addition, it should be established whether, after exercise, there is an association between increases in peripheral BDNF, increases in motor plasticity (e.g., enhanced TMS-probed corticospinal excitability and motor learning), and motor improvements. Findings from these studies are critical to expand our understanding of blood BDNF role in mediating exercise motor benefits via neural mechanisms (i.e., enhanced synaptic plasticity within the motor system).

\section{Peripheral Brain-Derived Neurotrophic Factor: Caveats and Limitations}

BDNF is present in most human tissues including brain and blood (Pruunsild et al., 2007; Serra-Millàs, 2016). The majority of blood BDNF is stored in platelet granules, from which it is released (degranulation) upon platelet activation (Yamamoto and Gurney, 1990; Fujimura et al., 2002). Non-neural sources of platelet-stored BDNF include vascular human endothelial cells, activated T and B cells and monocytes (Donovan et al., 1995, 2000; Kerschensteiner et al., 1999; Leventhal et al., 1999; Nakahashi et al., 2000). Also, more recently, Chacón-Fernández et al. (2016) found that platelet progenitors, megakaryocytes, express BDNF mRNA transcripts in a pattern similar to neurons. BDNF release from platelets takes place during clotting as supported by reports of a strong correlation between serum BDNF and serum serotonin, which is an indicator of platelet activation (Radka et al., 1996; Fujimura et al., 2002). Notably, shear stress, such as that caused by the syringe needle during blood collection, also induces BDNF release from platelet granules, particularly platelet release of BDNF due to shear stress is proportional to the strength of the stress (Fujimura et al., 2002). Peripheral BDNF can be measured in whole blood, plasma, and serum, however, its levels are between 100 and 200 fold 
higher in serum than plasma (Rosenfeld et al., 1995; Radka et al., 1996; Fujimura et al., 2002; Gejl et al., 2019). Given the difficulty of assessing brain BDNF concentrations in living humans, the presence of BDNF in blood has attracted considerable interest. Yet, quantification of peripheral BDNF levels is complicated by a number of methodological and non-methodological factors which introduce intra- and inter-individual variability in blood BDNF measures, impacting their reliability and reproducibility across studies (Figure 3). In particular, methodological and nonmethodological factors such as different anti-coagulants (e.g., ethylenediaminetetraacetic acid (EDTA) vs. heparin $v s$. citrate), temperature and length of time interval between collection of blood samples and their centrifugation, storage duration and temperature, body mass index, and age strongly affect plasma BDNF levels (Lommatzsch et al., 2005; Bus et al., 2011; Tsuchimine et al., 2014; Polyakova et al., 2017). Diurnal changes in plasma BDNF have also been reported with highest levels in the morning (i.e., 8:00 A.M.) and lowest at night (i.e., 12:00 A.M.) (Begliuomini et al., 2008; Piccinni et al., 2008; Pluchino et al., 2009). Similarly, serum BDNF levels are influenced by temperature during the time interval between collection of blood samples and their centrifugation as well as storage duration and temperature (Trajkovska et al., 2007; Bus et al., 2011; Elfving et al., 2012; Amadio et al., 2017). Another important determinant of serum BDNF levels is clotting duration as supported by the evidence that longer clotting duration is associated with higher serum BDNF levels with the lowest concentration being measured after $10 \mathrm{~min}$ of clotting and a plateau being reached at $\sim 1 \mathrm{~h}$ (Maffioletti et al., 2014; Gejl et al., 2019). Non-technical factors that affect serum BDNF levels include non-fasting state at blood collection, smoking, alcohol intake, medications, such as antidepressant venlafaxine and the antiplatelet medication clopidogrel (Aydemir et al., 2005; Sen et al., 2008; Bus et al., 2011; Stoll et al., 2011). Lastly, ELISA kits contribute to the intra- and inter-individual variability seen in peripheral BDNF concentrations. Indeed, Polacchini et al. (2015) showed that among five, commercially available, sandwich ELISA kits (i.e., Aviscera-Bioscience, Biosensis, Millipore-ChemiKine ${ }^{\mathrm{TM}}$, Promega-Emax ${ }^{\circledR}$, and R\&D System-Quantikine ${ }^{\circledR}$ ) for BDNF quantification, only one (Biosensis) had minimal inter-assay variability, thereby drawing attention to the need of using the same ELISA kit to measure BDNF across studies to limit result discrepancies.

Serum and plasma BDNF concentrations appear to reflect different pools of BDNF. BDNF in serum comes from platelet storage granules from which it is released during clotting (Fujimura et al., 2002; Maffioletti et al., 2014; Gejl et al., 2019). BDNF in plasma is thought to represent the small amount of free circulating BDNF, as plasma contains few platelets (Radka et al., 1996). During blood collection, however, platelets can release $\mathrm{BDNF}$ due to shear stress caused by the syringe needle and increase BDNF levels in plasma (Fujimura et al., 2002). Also, an increase in plasma BDNF can be due to release of BDNF from platelets occurring during the time interval between collection and centrifugation of blood samples (Elfving et al., 2010; Tsuchimine et al., 2014), as some degree of platelet activation and degranulation has been observed even in the presence of anticoagulants (e.g., EDTA-coated tubes) (Engstad et al., 1997; Ahnadi et al., 2003). These methodology-related sources of platelet-derived BDNF contribute to the considerable intra- and inter-individual variability of plasma BDNF measures $(\sim 100-$ $7,000 \mathrm{pg} / \mathrm{ml}$ ), impacting their reliability and reproducibility (Bocchio-Chiavetto et al., 2010; Polacchini et al., 2015; Gejl et al., 2019). Indeed, BDNF quantification in plasma appears to be heavily affected by methodological factors (e.g., shear stress at blood draw, temperature and length of time interval between collection of blood samples and their centrifugation, anticoagulants, storage temperature, and duration), to be greatly dependent on the experimenter, and thus, to ultimately be less reliable than serum BDNF measurements (Elfving et al., 2010; Tsuchimine et al., 2014; Polacchini et al., 2015; Polyakova et al., 2017). Stability of BDNF serum levels over a year and reliability of their measurements have been recently confirmed by Naegelin et al. (2018), who, however, emphasized the need, given individual variations, to examine large cohorts. Taken together, evidence from these studies encourages the use of serum over plasma when measuring peripheral BDNF to evaluate its contribution to exercise-induced motor benefits.

As direct measurements of brain BDNF levels cannot easily be performed in humans, quantification of peripheral BDNF concentrations has been used as a proxy. Animal studies have shown that BDNF crosses the blood-brain barrier (Poduslo and Curran, 1996; Pan et al., 1998; Alcalá-Barraza et al., 2010) and that there is a positive correlation between blood and brain BDNF levels, suggesting that changes in peripheral BDNF might reflect changes in brain BDNF (Karege et al., 2002; Sartorius et al., 2009; Klein et al., 2011). Nevertheless, it currently remains mostly speculative whether, in humans, changes in peripheral BDNF, e.g., following acute exercise, are a reliable proxy of changes in central (brain) BDNF. Measurement of the arterial-tointernal jugular venous concentration difference ( $a-v$ difference), as an indicator of cerebral outflow, has been used to test whether release of BDNF from the brain contributes to blood BDNF levels. Promisingly, using this approach, three studies have provided evidence for BDNF being released from the brain into the circulation both at rest (Dawood et al., 2007; Krabbe et al., 2007; Rasmussen et al., 2009) and during exercise (Rasmussen et al., 2009). In particular, Krabbe et al. (2007) showed cerebral BDNF output into circulation in healthy men at rest defined as the mean area under the curve for the $a-v$ difference being different from zero. Similarly, Dawood et al. (2007) reported a positive internal jugular veno-arterial BDNF plasma concentration gradient as well as higher BDNF levels in plasma obtained from internal jugular venous blood than in plasma obtained from brachial arterial blood, indicating that efflux of BDNF from the brain contributes to peripheral BDNF concentrations at rest in patients with major depressive disorder. Lastly, Rasmussen et al. (2009) confirmed cerebral output of BDNF into circulation via the internal jugular vein at rest in healthy men as indicated by the $a-v$ difference being different from zero and showed a two- to three-fold increase in the $a-v$ difference (i.e., increased central BDNF outflow) with prolonged exercise (i.e., $4 \mathrm{~h}$ of ergometer rowing). Collectively, these findings support the hypothesis that blood BDNF levels 


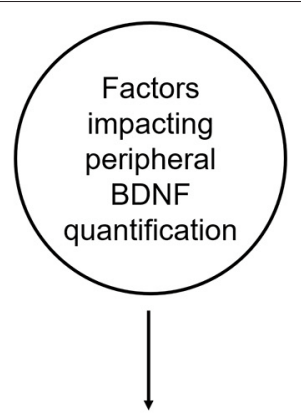

\begin{tabular}{|l|}
\hline \multicolumn{1}{|c|}{ in PLASMA } \\
(free circulating BDNF): \\
- shear stress caused by syringe needle at \\
blood draw \\
100-200 fold less BDNF than serum \\
- time of day at blood draw i.e., highest \\
levels at 8:00 AM and lowest at 12:00 PM \\
anticoagulants i.e., EDTA vs. heparin vs. \\
citrate \\
body mass index \\
- age
\end{tabular}

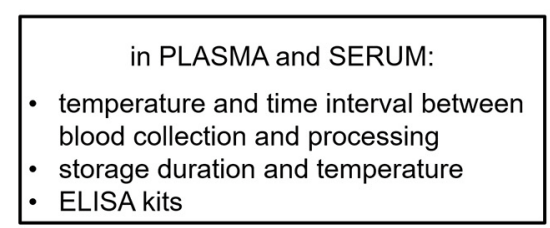

FIGURE 3 | Methodological and non-methodological factors introducing intra- and inter-variability in peripheral brain-derived neurotrophic factor quantification. BDNF, brain-derived neurotrophic factor; EDTA, ethylenediaminetetraacetic acid; ELISA, enzyme-linked immunosorbent assay. reflect brain BDNF levels and the use of peripheral BDNF measures to expand our understanding of the neural mechanisms behind exercise benefits.

\section{FUTURE AVENUES}

Although exercise upregulates peripheral BDNF (Knaepen et al., 2010; Zoladz and Pilc, 2010; Gomes de Melo Coelho et al., 2013a; Huang et al., 2014; Szuhany et al., 2015; Dinoff et al., 2017; Mackay et al., 2017; Marinus et al., 2019; de Azevedo et al., 2020), it is still unclear whether increases in peripheral BDNF mediate exercise effects on mobility, gait, balance, and motor control. To date, findings are few and conflicting (Mang et al., 2014; Skriver et al., 2014; Helm et al., 2017). Evaluation of exercise-induced increases in peripheral BDNF, motor plasticity (e.g., enhanced TMS-probed corticospinal excitability and motor learning), and motor outcomes (i.e., improved mobility, gait, balance, and motor control) within a single study is key to advancing our understanding. It is indeed essential to garner evidence at different levels of analysis (i.e., systemic, molecular, behavioral) within the same study to unveil the mechanistic link between exercise and motor improvements, and to thus, gain the knowledge needed to successfully employ exercise protocols in preventing, delaying, and off-setting age- and disease-related motor deficits.

A single nucleotide polymorphism (Val66Met, rs6265) in the BDNF gene, causing a valine-to-methionine substitution, reduces activity-dependent release of BDNF (Egan et al., 2003) and could, thereby, attenuate BNDF-driven, priming effects of exercise on neuroplasticity, motor learning, and, ultimately, on motor outcomes (i.e., mobility, gait, balance, and motor control). Current evidence is limited and mixed. Andrews et al. (2020) showed that BDNF Val66Met polymorphism reduced exercise priming effects on plasticity within the primary motor cortex, while McDonnell et al. (2013) and Singh et al. (2014) reported no effect. However, Singh et al. (2014) might not have been adequately powered ( $n=6$, Met carriers; $n=6$, Val/Val) to detect whether BDNF genotype impacts exercise effects on motor plasticity, measured using different repetitive transcranial magnetic stimulation paradigms. Of note, Met carriers showed a trend toward a stronger reduction in $\mathrm{GABA}_{\mathrm{A}}$-mediated inhibition (i.e., lower short-interval intracortical inhibition) than $\mathrm{Val} / \mathrm{Val}$ homozygotes and no change in $\mathrm{GABA}_{\mathrm{B}}$-mediated inhibition (i.e., long-interval intracortical inhibition) (Singh et al., 2014), underlining the need to investigate further the effects of BDNF Val66Met polymorphism on exercise priming of motor plasticity. Lastly, although there are two reports that BDNF genotype does not affect exercise effects on motor learning (Helm et al., 2017; Mang et al., 2017), it remains to be assessed whether it attenuates exercise-induced motor improvements in healthy, aging, or clinical populations. Identifying potential determinants of individual variation, such as BDNF Val66Met polymorphism, is important for the design of personalized exercise strategies aimed at maximizing priming of neuroplasticity and thus motor improvements in both physiological and rehabilitative settings.

As methodological and non-methodological factors influence quantification of peripheral BDNF concentrations (Aydemir et al., 2005; Lommatzsch et al., 2005; Trajkovska et al., 2007; Begliuomini et al., 2008; Piccinni et al., 2008; Sen et al., 2008; Pluchino et al., 2009; Bus et al., 2011; Choi et al., 2011; Stoll 
TABLE 1 | Recommendations based on current evidence to reduce intra- and inter-variability in peripheral brain-derived neurotrophic factor quantification.

\begin{tabular}{|c|c|}
\hline Best practice & Reference \\
\hline \multirow[t]{4}{*}{ Serum over plasma } & Elfving et al., 2010 \\
\hline & Polacchini et al., 2015 \\
\hline & Polyakova et al., 2017 \\
\hline & Naegelin et al., 2018 \\
\hline \multirow[t]{2}{*}{ Clotting time from $30 \mathrm{~min}$ to $1 \mathrm{~h}$} & Maffioletti et al., 2014 \\
\hline & Gejl et al., 2019 \\
\hline Biosensis ELISA kit & Polacchini et al., 2015 \\
\hline \multirow[t]{4}{*}{ Blood collection time between 7:00 A.M. and 8:00 A.M. } & Begliuomini et al., 2008 \\
\hline & Piccinni et al., 2008 \\
\hline & Pluchino et al., 2009 \\
\hline & Choi et al., 2011 \\
\hline 12-h fast prior to blo & Bus et al., 2011 \\
\hline
\end{tabular}

et al., 2011; Maffioletti et al., 2014; Tsuchimine et al., 2014; Polacchini et al., 2015; Amadio et al., 2017; Polyakova et al., 2017; Naegelin et al., 2018; Gejl et al., 2019), the lack of a standardized protocol currently hinders result interpretation and comparison and leads to discrepancies among studies. To limit variability in blood BDNF measures and reduce inconsistencies, future studies should aim at developing a standardized, reliable protocol for peripheral BDNF quantification. By increasing result reproducibility, such a protocol would help draw reliable conclusions on whether peripheral BDNF mediates exerciserelated motor benefits.

Exercise might not only increase total levels of BDNF, but also the speed of BDNF release. In other words, BDNF might be released faster into serum during clotting after exercise than following a period of rest of comparable length. Interestingly, Gejl et al. (2019), despite failing to find a significant correlation between cardiorespiratory fitness and serum BDNF levels, observed a switch from a positive correlation at $30 \mathrm{~min}$ of clotting to a negative one at $60 \mathrm{~min}$ and at longer clotting times $(180,240$, and $300 \mathrm{~min})$ as well as a negative correlation between cardiorespiratory fitness and the difference in serum BDNF measured at 30 and at $60 \mathrm{~min}$ of clotting. These findings suggest that greater cardiorespiratory fitness is associated with a faster initial release of BDNF into serum during clotting and with less BDNF being released at $60 \mathrm{~min}$ and at longer clotting times (Gejl et al., 2019). Effects of exercise (i.e., acute and training) on the rate of BDNF should be further assessed in future studies.

\section{DISCUSSION}

Being a key mediator of neuroplasticity (Lu et al., 2014; Gibon and Barker, 2017; Leal et al., 2017; Kowiański et al., 2018), which has been shown to underpin motor learning (RioultPedotti et al., 2000; Muellbacher et al., 2002; Doyon and Benali,
2005; Monfils et al., 2005; McConnell et al., 2009; Dayan and Cohen, 2011; Cantarero et al., 2013), BDNF is likely to play an important role in mediating the beneficial effects of exercise on mobility, gait, balance, and motor control. Currently, however, only two studies have investigated whether BDNF contributes to exercise-induced motor improvements (Mang et al., 2014; Skriver et al., 2014). Skriver et al. (2014) reported a relationship between BDNF increases and gains in motor skill acquisition and retention following exercise, while Mang et al. (2014) failed to find one. It is thereby clear that it needs to be further investigated whether BDNF is mechanistically linked to exerciseinduced motor benefits. To this end, given the difficulties of obtaining direct measures of brain BDNF concentrations in humans, it is crucial to be able to reliably measure peripheral BDNF levels so that results are reproducible and can be compared among studies. Intra- and inter-individual variability in peripheral BDNF concentrations (Bocchio-Chiavetto et al., 2010; Fernandes et al., 2011; Suliman et al., 2013) currently hinders interpretation of findings, result comparisons, and the ability to draw reliable conclusions, impeding our understanding of how exercise promotes neuroplasticity and thus improves mobility, gait, balance, and motor control. Methodological and non-methodological (e.g., sociodemographic, lifestyle) factors that affect quantification of BDNF blood levels and are a source of discrepancies among studies include temperature and length of time between collection of blood samples and their centrifugation, centrifugation speed and duration, storage temperature and duration, number of freeze/thaw cycles, ELISA kits used for quantification, non-fasting state at blood draw, time of day at which blood samples are collected, medications, age, body mass index, menstrual cycle phase, smoking, and alcohol intake (Aydemir et al., 2005; Lommatzsch et al., 2005; Trajkovska et al., 2007; Begliuomini et al., 2008; Piccinni et al., 2008; Sen et al., 2008; Pluchino et al., 2009; Elfving et al., 2010, 2012; Bus et al., 2011; Choi et al., 2011; Stoll et al., 2011; Maffioletti et al., 2014; Tsuchimine et al., 2014; Polacchini et al., 2015; Amadio et al., 2017; Polyakova et al., 2017; Naegelin et al., 2018; Gejl et al., 2019). The evidence that methodological factors profoundly influence quantification of peripheral BDNF calls attention to the importance of exercising caution in the methodology used to measure blood BDNF concentrations and to the pressing need for a standardized protocol across studies. Indeed, a standardized protocol encompassing all steps of peripheral BDNF detection, including participant selection criteria (e.g., body mass index, age, medications, smoking, alcohol intake), blood collection (e.g., time of day, fasting state, time interval between collection and processing, temperature during this interval), processing (e.g., clotting duration, centrifugation speed, and duration), storage (e.g., temperature, duration), and BDNF quantification (i.e., ELISA kit used), should be developed and used for quantification of peripheral BDNF concentrations across studies. Based on findings garnered thus far, it appears that to reduce intra- and inter-variability in peripheral BDNF measures serum should be preferred over plasma (Elfving et al., 2010; Polacchini et al., 2015; Polyakova et al., 2017; Naegelin et al., 2018), serum samples should be allowed to clot a minimum of $30 \mathrm{~min}$ up to $1 \mathrm{~h}$ (Maffioletti et al., 2014; Gejl et al., 2019), Biosensis ELISA kit 
should be used for BDNF quantification (Polacchini et al., 2015), and blood should be collected in the morning (i.e., 8:00 A.M.) (Begliuomini et al., 2008; Piccinni et al., 2008; Pluchino et al., 2009; Choi et al., 2011) from fasting participants (Table 1; Bus et al., 2011). In addition, medications, body mass index, age, menstrual cycle phase, smoking, and alcohol intake should be taken into account when recruiting participants (Aydemir et al., 2005; Lommatzsch et al., 2005; El-Gharbawy et al., 2006; Ziegenhorn et al., 2007; Sen et al., 2008; Pluchino et al., 2009; Bus et al., 2011; Stoll et al., 2011; Cho et al., 2012; Elfving et al., 2012; Jamal et al., 2015). By reducing the considerable result variability in blood BDNF concentrations and thus providing reproducible results, such a protocol is highly valuable in expanding our understanding of how exercise improves

\section{REFERENCES}

Ahnadi, C. E., Chapman, E. S., Lépine, M., Okrongly, D., Pujol-Moix, N., Hernández, A., et al. (2003). Assessment of platelet activation in several different anticoagulants by the advia 120 hematology system, fluorescence flow cytometry, and electron microscopy. Thromb. Haemost. 90, 940-948. doi: 10.1160/TH03-02-0097

Alcalá-Barraza, S. R., Lee, M. S., Hanson, L. R., McDonald, A. A., Frey, W. H. II., and McLoon, L. K. (2010). Intranasal delivery of neurotrophic factors BDNF, CNTF, EPO, and NT-4 to the CNS. J. Drug Target 18, 179-190. doi: 10.3109/10611860903318134

Amadio, P., Sandrini, L., Ieraci, A., Tremoli, E., and Barbieri, S. S. (2017). Effect of clotting duration and temperature on BDNF measurement in human serum. Int. J. Mol. Sci. 18:1987. doi: 10.3390/ijms18091987

Andrews, S. C., Curtin, D., Hawi, Z., Wongtrakun, J., Stout, J. C., and Coxon, J. P. (2020). Intensity matters: high-intensity interval exercise enhances motor cortex plasticity more than moderate exercise. Cereb. Cortex 30, 101-112. doi: 10.1093/cercor/bhz075

Antunes, B. M., Rossi, F. E., Teixeira, A. M., and Lira, F. S. (2020). Short-time high-intensity exercise increases peripheral BDNF in a physical fitness-dependent way in healthy men. Eur. J. Sport Sci. 20, 43-50. doi: 10.1080/17461391.2019.1611929

Armeanu, R., Mokkonen, M., and Crespi, B. (2017). Meta-Analysis of BDNF levels in autism. Cell Mol. Neurobiol. 37, 949-954. doi: 10.1007/s10571-016-0415-7

Aydemir, O., Deveci, A., and Taneli, F. (2005). The effect of chronic antidepressant treatment on serum brain-derived neurotrophic factor levels in depressed patients: a preliminary study. Prog. Neuropsychopharmacol. Biol. Psychiatry 29, 261-265. doi: 10.1016/j.pnpbp.2004.11.009

Baird, J. F., Gaughan, M. E., Saffer, H. M., Sarzynski, M. A., Herter, T. M., Fritz, S. L., et al. (2018). The effect of energy-matched exercise intensity on brainderived neurotrophic factor and motor learning. Neurobiol. Learn. Mem. 156, 33-44. doi: 10.1016/j.nlm.2018.10.008

Baker, L. D., Frank, L. L., Foster-Schubert, K., Green, P. S., Wilkinson, C. W., McTiernan, A., et al. (2010). Effects of aerobic exercise on mild cognitive impairment: a controlled trial. Arch. Neurol. 67, 71-79. doi: 10.1001/archneurol.2009.307

Bansi, J., Bloch, W., Gamper, U., and Kesselring, J. (2013). Training in MS: influence of two different endurance training protocols (aquatic versus overland) on cytokine and neurotrophin concentrations during three week randomized controlled trial. Multi. Scler. 19, 613-621. doi: $10.1177 / 1352458512458605$

Barde, Y. A. (1994). Neurotrophins: a family of proteins supporting the survival of neurons. Prog. Clin. Biol. Res. 390, 45-56.

Barde, Y. A., Edgar, D., and Thoenen, H. (1982). Purification of a new neurotrophic factor from mammalian brain. EMBO J. 1, 549-553. doi: 10.1002/j.1460-2075.1982.tb01207.x

Begliuomini, S., Lenzi, E., Ninni, F., Casarosa, E., Merlini, S., Pluchino, N., et al. (2008). Plasma brain-derived neurotrophic factor daily variations in mobility, gait, balance, and motor control in physiological and rehabilitative settings.

\section{AUTHOR CONTRIBUTIONS}

$\mathrm{CN}$ wrote, reviewed, and edited the manuscript. AJN funded, reviewed, and edited the manuscript. All authors have read and approved the final manuscript.

\section{FUNDING}

This work was supported by a grant from the Natural Sciences and Engineering Research Council of Canada (NSERC) and Canada Research Chair program to AJN. men: correlation with cortisol circadian rhythm. J. Endocrinol. 197, 429-435. doi: 10.1677/JOE-07-0376

Bekinschtein, P., Cammarota, M., Katche, C., Slipczuk, L., Rossato, J. I., Goldin, A., et al. (2008). BDNF is essential to promote persistence of long-term memory storage. Proc. Natl. Acad. Sci. U.S.A. 105, 2711-2716. doi: $10.1073 /$ pnas.0711863105

Binder, D. K., and Scharfman, H. E. (2004). Brain-derived neurotrophic factor. Growth Factors 22, 123-131. doi: 10.1080/08977190410001723308

Blankevoort, C. G., Heuvelen, M. J. G., Boersma, F., Luning, H., Jong, J., and Scherder, E. J. A. (2010). Review of effects of physical activity on strength, balance, mobility and ADL performance in elderly subjects with dementia. Dement. Geriatr. Cogn. Disord. 30, 392-402. doi: 10.1159/000321357

Bocchio-Chiavetto, L., Bagnardi, V., Zanardini, R., Molteni, R., Nielsen, M. G., Placentino, A., et al. (2010). Serum and plasma BDNF levels in major depression: a replication study and meta-analyses. World J. Biol. Psychiatry 11, 763-773. doi: 10.3109/15622971003611319

Bolandzadeh, N., Tam, R., Handy, T. C., Nagamatsu, L. S., Hsu, C. L., Davis, J. C. et al. (2015). Resistance training and white matter lesion progression in older women: exploratory analysis of a 12-month randomized controlled trial. J. Am. Geriatr. Soc. 63, 2052-2060. doi: 10.1111/jgs.13644

Bos, I., Jacobs, L., Nawrot, T. S., de Geus, B., Torfs, R., Int Panis, L., et al. (2011). No exercise-induced increase in serum BDNF after cycling near a major traffic road. Neurosci. Lett. 500, 129-132. doi: 10.1016/j.neulet.2011.06.019

Brach, J. S., Perera, S., Gilmore, S., VanSwearingen, J. M., Brodine, D., Nadkarni, N. K., et al. (2017). Effectiveness of a timing and coordination group exercise program to improve mobility in community-dwelling older adults: a randomized clinical trial. JAMA Intern. Med. 177, 1437-1444. doi: 10.1001/jamainternmed.2017.3609

Bramham, C. R., and Messaoudi, E. (2005). BDNF function in adult synaptic plasticity: the synaptic consolidation hypothesis. Prog. Neurobiol. 76, 99-125. doi: 10.1016/j.pneurobio.2005.06.003

Brienesse, L. A., and Emerson, M. N. (2013). Effects of resistance training for people with Parkinson's disease: a systematic review. J. Am. Med. Dir. Assoc. 14, 236-241. doi: 10.1016/j.jamda.2012.11.012

Brunoni, A. R., Lopes, M., and Fregni, F. (2008). A systematic review and metaanalysis of clinical studies on major depression and BDNF levels: implications for the role of neuroplasticity in depression. Int. J. Neuropsychopharmacol. 11, 1169-1180. doi: 10.1017/S1461145708009309

Buckwalter, J. (1997). Decreased mobility in the elderly: the exercise antidote. Phys. Sport. 25, 126-133. doi: 10.3810/psm.1997.09.1516

Bus, B. A. A., Molendijk, M. L., Penninx, B. J. W. H., Buitelaar, J. K., Kenis, G., Prickaerts, J., et al. (2011). Determinants of serum brainderived neurotrophic factor. Psychoneuroendocrinology 36, 228-239. doi: 10.1016/j.psyneuen.2010.07.013

Campbell, A. J., Robertson, M. C., Gardner, M. M., Norton, R. N., and Buchner, D. M. (1999). Falls prevention over 2 years: a randomized controlled trial in women 80 years and older. Age Ageing 28, 513-518. doi: 10.1093/ageing/28.6.513 
Cantarero, G., Tang, B., O’Malley, R., Salas, R., and Celnik, P. (2013). Motor learning interference is proportional to occlusion of LTP-like plasticity. J. Neurosci. 33, 4634-4641. doi: 10.1523/JNEUROSCI.4706-1 2.2013

Carlino, D., Leone, E., Cola, F., Di, B. G., Marin, R., Dinelli, G., et al. (2011). Low serum truncated-BDNF isoform correlates with higher cognitive impairment in schizophrenia. J. Psychiatr. Res. 45, 273-279. doi: 10.1016/j.jpsychires.2010.06.012

Carlino, D., Vanna, M., and Tongiorgi, E. (2013). Is altered BDNF biosynthesis a general feature in patients with cognitive dysfunctions? Neuroscientist 19, 345-353. doi: 10.1177/1073858412469444

Chacón-Fernández, P., Säuberli, K., Colzani, M., Moreau, T., Ghevaert, C., and Barde, Y.-A. (2016). Brain-derived neurotrophic factor in megakaryocytes. J. Biol. Chem. 291, 9872-9881. doi: 10.1074/jbc.M116.720029

Chapleau, C. A., Larimore, J. L., Theibert, A., and Pozzo-Miller, L. (2009). Modulation of dendritic spine development and plasticity by BDNF and vesicular trafficking: fundamental roles in neurodevelopmental disorders associated with mental retardation and autism. J. Neurodev. Disord. 1, 185-196. doi: 10.1007/s11689-009-9027-6

Cho, H., Kim, J., Kim, S., Son, Y. H., Lee, N., and Jung, S. H. (2012). The concentrations of serum, plasma and platelet BDNF are all increased by treadmill VO2max performance in healthy college men. Neurosci. Lett. 519, 78-83. doi: 10.1016/j.neulet.2012.05.025

Choi, S.-W., Bhang, S., and Ahn, J.-H. (2011). Diurnal variation and gender differences of plasma brain-derived neurotrophic factor in healthy human subjects. Psychiatry Res 186, 427-430. doi: 10.1016/j.psychres.2010.07.028

Colcombe, S. J., Erickson, K. I., Raz, N., Webb, A. G., Cohen, N. J., McAuley, E., et al. (2003). Aerobic fitness reduces brain tissue loss in aging humans. J. Gerontol. A Biol. Sci. Med. Sci. 58, 176-180. doi: 10.1093/gerona/58.2.M176

Colcombe, S. J., Erickson, K. I., Scalf, P. E., Kim, J. S., Prakash, R., McAuley, E., et al. (2006). Aerobic exercise training increases brain volume in aging humans. J. Gerontol. A Biol. Sci. Med. Sci. 61, 1166-1170. doi: 10.1093/gerona/61.11.1166

Cooke, E. V., Mares, K., Clark, A., Tallis, R. C., and Pomeroy, V. M. (2010). The effects of increased dose of exercise-based therapies to enhance motor recovery after stroke: a systematic review and meta-analysis. BMC Med. 8:60. doi: 10.1186/1741-7015-8-60

Correia, P. R., Pansani, A., Machado, F., Andrade, M., Silva, A. C., Scorza, F. A., et al. (2010). Acute strength exercise and the involvement of small or large muscle mass on plasma brain-derived neurotrophic factor levels. Clinics 65, 1123-1126. doi: 10.1590/S1807-59322010001100012

Crizzle, A. M., and Newhouse, I. J. (2006). Is physical exercise beneficial for persons with Parkinson's disease? Clinics. 16, 422-425. doi: 10.1097/01.jsm.0000244612.55550.7d

Cugusi, L., Manca, A., Bergamin, M., Blasio, A., Monticone, M., Deriu, F., et al. (2019). Aquatic exercise improves motor impairments in people with Parkinson's disease, with similar or greater benefits than land-based exercise: a systematic review. J. Physiother. 65, 65-74. doi: 10.1016/j.jphys.2019.02.003

Dal Maso, F., Desormeau, B., Boudrias, M.-H., and Roig, M. (2018). Acute cardiovascular exercise promotes functional changes in cortico-motor networks during the early stages of motor memory consolidation. Neuroimage 174, 380-392. doi: 10.1016/j.neuroimage.2018.03.029

Dawood, T., Anderson, J., Barton, D., Lambert, E., Esler, M., Hotchkin, E., et al. (2007). Reduced overflow of BDNF from the brain is linked with suicide risk in depressive illness. Mol. Psychiatry 12, 981-983. doi: 10.1038/sj.mp.4002059

Dayan, E., and Cohen, L. G. (2011). Neuroplasticity subserving motor skill learning. Neuron 72, 443-454. doi: 10.1016/j.neuron.2011.10.008

de Azevedo, K. P. M., de Oliveira, V. H., de Medeiros, B. S. C. G., de Sousa Mata, Á. N., García, D. Á., Martínez, D. G., et al. (2020). The effects of exercise on BDNF levels in adolescents: a systematic review with meta-analysis. Int. J. Env. Res. Public Heal. 17:6065. doi: 10.3390/ijerph17176056

Deandrea, S., Lucenteforte, E., Bravi, F., Foschi, R., La Vecchia, C., and Negri, E. (2010). Risk factors for falls in community-dwelling older people: a systematic review and meta-analysis. Epidemiology 21, 658-668. doi: 10.1097/EDE.0b013e3181e89905

Dennett, A. M., Peiris, C. L., Shields, N., Prendergast, L. A., and Taylor, N. F. (2016). Moderate-intensity exercise reduces fatigue and improves mobility in cancer survivors: a systematic review and meta-regression. J. Physiother. 62, 68-82. doi: 10.1016/j.jphys.2016.02.012
Di Carlo, P., Punzi, G., and Ursini, G. (2019). Brain-derived neurotrophic factor and schizophrenia. Psychiatr. Genet. 29, 200-210. doi: 10.1097/YPG.0000000000000237

Dinoff, A., Herrmann, N., Swardfager, W., and Lanctôt, K. L. (2017). The effect of acute exercise on blood concentrations of brain-derived neurotrophic factor in healthy adults: a meta-analysis. Eur. J. Neurosci. 46, 1635-1646. doi: 10.1111/ejn.13603

Donovan, M. J., Lin, M. I., Wiegn, P., Ringstedt, T., Kraemer, R., Hahn, R., et al. (2000). Brain derived neurotrophic factor is an endothelial cell survival factor required for intramyocardial vessel stabilization. Development 127, 4531-4540. doi: 10.1242/dev.127.21.4531

Donovan, M. J., Miranda, R. C., Kraemer, R., McCaffrey, T. A., Tessarollo, L., Mahadeo, D., et al. (1995). Neurotrophin and neurotrophin receptors in vascular smooth muscle cells. Regulation of expression in response to injury. Am. J. Pathol. 147, 309-324.

Doyon, J., and Benali, H. (2005). Reorganization and plasticity in the adult brain during learning of motor skills. Curr. Opin. Neurobiol. 15, 161-167. doi: 10.1016/j.conb.2005.03.004

Duchesne, C., Gheysen, F., Bore, A., Albouy, G., Nadeau, A., Robillard, M. E., et al. (2016). Influence of aerobic exercise training on the neural correlates of motor learning in Parkinson's disease individuals. NeuroImage Clin. 12, 559-569. doi: 10.1016/j.nicl.2016.09.011

Duchesne, C., Lungu, O., Nadeau, A., Robillard, M. E., Boré, A., Bobeuf, F., et al. (2015). Enhancing both motor and cognitive functioning in Parkinson's disease: aerobic exercise as a rehabilitative intervention. Brain Cogn. 99, 68-77. doi: 10.1016/j.bandc.2015.07.005

Egan, M. F., Kojima, M., Callicott, J. H., Goldberg, T. E., Kolachana, B. S., Bertolino, A., et al. (2003). The BDNF val66met polymorphism affects activitydependent secretion of BDNF and human memory and hippocampal function. Cell 112, 257-269. doi: 10.1016/S0092-8674(03)00035-7

Elfving, B., Buttenschøn, H. N., Foldager, L., Poulsen, P. H. P., Andersen, J. H., Grynderup, M. B., et al. (2012). Depression, the Val66Met polymorphism, age, and gender influence the serum BDNF level. J. Psychiatr. Res. 46, 1118-1125. doi: 10.1016/j.jpsychires.2012.05.003

Elfving, B., Plougmann, P. H., and Wegener, G. (2010). Detection of brainderived neurotrophic factor (BDNF) in rat blood and brain preparations using ELISA: pitfalls and solutions. J. Neurosci. Methods 187, 73-77. doi: 10.1016/j.jneumeth.2009.12.017

El-Gharbawy, A. H., Adler-Wailes, D. C., Mirch, M. C., Theim, K. R., Ranzenhofer, L., Tanofsky-Kraff, M., et al. (2006). Serum brain-derived neurotrophic factor concentrations in lean and overweight children and adolescents. J. Clin. Endocrinol. Metab. 91, 3548-3552. doi: 10.1210/jc.2006-0658

Enette, L., Vogel, T., Fanon, J. L., and Lang, P. O. (2017). Effect of interval and continuous aerobic training on basal serum and plasma brain-derived neurotrophic factor values in seniors: a systematic review of intervention studies. Rejuvenation Res. 20, 473-483. doi: 10.1089/rej.2016.1886

Engstad, C. S., Gutteberg, T. J., and Osterud, B. (1997). Modulation of blood cell activation by four commonly used anticoagulants. Thromb. Haemost. 77, 690-696. doi: 10.1055/s-0038-1656035

Erickson, K. I., Voss, M. W., Prakash, R. S., Basak, C., Szabo, A., Chaddock, L., et al. (2011). Exercise training increases size of hippocampus and improves memory. Proc. Natl. Acad. Sci. U.S.A. 108, 3017-3022. doi: 10.1073/pnas.1015950108

Fahnestock, M. (2011). Brain-derived neurotrophic factor: the link between amyloid- $\beta$ and memory loss. Future Neurol. 6, 627-639. doi: 10.2217/fnl.11.44

Fahnestock, M., and Nicolini, C. (2015). Bridging the gap between genes and behavior: brain-derived neurotrophic factor and the mTOR pathway in idiopathic autism. Autism Open Access 5:143. doi: 10.4172/2165-7890.1000143

Fasano, A., Canning, C. G., Hausdorff, J. M., Lord, S., and Rochester, L. (2017). Falls in Parkinson's disease: a complex and evolving picture. Mov. Disord. 32, 1524-1536. doi: 10.1002/mds. 27195

Fernandes, B. S., Gama, C. S., Ceresér, K. M., Yatham, L. N., Fries, G. R., Colpo, G., et al. (2011). Brain-derived neurotrophic factor as a state-marker of mood episodes in bipolar disorders: a systematic review and meta-regression analysis. J. Psychiatr. Res. 45, 995-1004. doi: 10.1016/j.jpsychires.2011. 03.002

Ferris, L. T., Williams, J. S., and Shen, C.-L. (2007). The effect of acute exercise on serum brain-derived neurotrophic factor levels and cognitive function. Med. Sci. Sport Exerc. 39, 728-734. doi: 10.1249/mss.0b013e31802f04c7 
Fisher, B. E., Wu, A. D., Salem, G. J., Song, J., Lin, C. H., Yip, J., et al. (2008). The effect of exercise training in improving motor performance and corticomotor excitability in people with early Parkinson's disease. Arch. Phys. Med. Rehabil. 89, 1221-1229. doi: 10.1016/j.apmr.2008.01.013

Forrester, L. W., Wheaton, L. A., and Luft, A. R. (2008). Exercise-mediated locomotor recovery and lower-limb neuroplasticity after stroke. J. Rehabil. Res. Dev. 45, 205-220. doi: 10.1682/JRRD.2007.02.0034

Fritsch, B., Reis, J., Martinowich, K., Schambra, H. M., Ji, Y., Cohen, L. G., et al. (2010). Direct current stimulation promotes BDNF-dependent synaptic plasticity: potential implications for motor learning. Neuron 66, 198-204. doi: 10.1016/j.neuron.2010.03.035

Fujimura, H., Altar, C. A., Chen, R., Nakamura, T., Nakahashi, T., Kambayashi, J., et al. (2002). Brain-derived neurotrophic factor is stored in human platelets and released by agonist stimulation. Thromb. Haemost. 87, 728-734. doi: 10.1055/s-0037-1613072

Garcia, K. L. P., Yu, G., Nicolini, C., Michalski, B., Garzon, D. J., Chiu, V. S., et al. (2012). Altered balance of proteolytic isoforms of pro-brain-derived neurotrophic factor in autism. J. Neuropathol. Exp. Neurol. 71, 289-297. doi: 10.1097/NEN.0b013e31824b27e4

Gejl, A. K., Enevold, C., Bugge, A., Andersen, M. S., Nielsen, C. H., and Andersen, L. B. (2019). Associations between serum and plasma brain-derived neurotrophic factor and influence of storage time and centrifugation strategy. Sci. Rep. 9:9655. doi: 10.1038/s41598-019-45976-5

Gibon, J., and Barker, P. A. (2017). Neurotrophins and proneurotrophins: focus on synaptic activity and plasticity in the brain. Neuroscientist 23, 587-604. doi: $10.1177 / 1073858417697037$

Gobbi, L. T. B., Oliveira-Ferreira, M. D. T., Caetano, M. J. D., Lirani-Silva, E., Barbieri, F. A., Stella, F., et al. (2009). Exercise programs improve mobility and balance in people with Parkinson's disease. Park. Relat. Disord. 15, S49-S52. doi: 10.1016/S1353-8020(09)70780-1

Goekint, M., Heyman, E., Roelands, B., Njemini, R., Bautmans, I., Mets, T., et al. (2008). No influence of noradrenaline manipulation on acute exerciseinduced increase of brain-derived neurotrophic factor. Med. Sci. Sport Exerc. 40, 1990-1996. doi: 10.1249/MSS.0b013e31817eee85

Goekint, M., Pauw, K., Roelands, B., Njemini, R., Bautmans, I., Mets, T., et al. (2010). Strength training does not influence serum brain-derived neurotrophic factor. Eur. J. Appl. Physiol. 110, 285-293. doi: 10.1007/s00421-010-1461-3

Gold, S. M., Schulz, K.-H., Hartmann, S., Mladek, M., Lang, U. E., Hellweg, R., et al. (2003). Basal serum levels and reactivity of nerve growth factor and brain-derived neurotrophic factor to standardized acute exercise in multiple sclerosis and controls. J. Neuroimmunol. 138, 99-105. doi: 10.1016/S0165-5728(03)00121-8

Goldfield, G. S., Kenny, G. P., Prud'homme, D., Holcik, M., Alberga, A. S., Fahnestock, M., et al. (2018). Effects of aerobic training, resistance training, or both on brain-derived neurotrophic factor in adolescents with obesity: the hearty randomized controlled trial. Physiol. Behav. 191, 138-145. doi: 10.1016/j.physbeh.2018.04.026

Goldfield, G. S., Kenny, G. P., Prud'homme, D., Holcik, M., Alberga, A. S., Fahnestock, M., et al. (2019). Corrigendum to "effects of aerobic training, resistance training, or both on brain-derived neurotrophic factor in adolescents with obesity: the hearty randomized controlled trial" physiology \& behavior, volume 191, 1 July 2018, pages 138-145. Physiol. Behav. 198:161. doi: 10.1016/j.physbeh.2018.06.019

Gomes de Melo Coelho, F., Gobbi, S., Almeida Andreatto, C. A., Icassati Corazza, D., Valle Pedroso, R., and Ferreira Santos-Galduróz, R. (2013a). Physical exercise modulates peripheral levels of brain-derived neurotrophic factor (BDNF): a systematic review of experimental studies in the elderly. Arch. Gerontol. Geriatr. 56, 10-15. doi: 10.1016/j.archger.2012.06.003

Gomes de Melo Coelho, F., Pires Andrade, L., Valle Pedroso, R., Ferreira Santos-Galduroz, R., Gobbi, S., Riani Costa, J. L., et al. (2013b). Multimodal exercise intervention improves frontal cognitive functions and gait in Alzheimer's disease: a controlled trial. Geriatr. Gerontol. Int. 13, 198-203. doi: 10.1111/j.1447-0594.2012.00887.x

Gomes de Melo Coelho, F., Vital, T. M., Stein, A. M., Arantes, F. J., Veloso Rueda, A., Camarini, R., et al. (2014). Acute aerobic exercise increases brain-derived neurotrophic factor levels in elderly with Alzheimer's disease. J. Alzheimers Dis. 39, 401-408. doi: 10.3233/JAD-131073
Gómez-Pinilla, F., Ying, Z., Roy, R. R., Molteni, R., and Edgerton, V. R. (2002). Voluntary exercise induces a bdnf-mediated mechanism that promotes neuroplasticity. J. Neurophysiol. 88, 2187-2195. doi: 10.1152/jn.00152.2002

Goodwin, V. A., Richards, S. H., Taylor, R. S., Taylor, A. H., and Campbell, J. L. (2008). The effectiveness of exercise interventions for people with Parkinson's disease: a systematic review and meta-analysis. Mov. Disord. 23, 631-640. doi: $10.1002 / \mathrm{mds} .21922$

Gourgouvelis, J., Yielder, P., Clarke, S. T., Behbahani, H., and Murphy, B. (2018). You can't fix what isn't broken: eight weeks of exercise do not substantially change cognitive function and biochemical markers in young and healthy adults. PeerJ 6:e4675. doi: 10.7717/peerj.4675

Green, M. J., Matheson, S. L., Shepherd, A., Weickert, C. S., and Carr, V. J. (2011). Brain-derived neurotrophic factor levels in schizophrenia: a systematic review with meta-analysis. Mol. Psychiatry 16, 960-972. doi: 10.1038/mp.2010.88

Gretebeck, K. A., Blaum, C. S., Moore, T., Brown, R., Galecki, A., Strasburg, D., et al. (2019). Functional exercise improves mobility performance in older adults with type 2 diabetes: a randomized controlled trial. J. Phys. Act. Health 16, 461-469. doi: 10.1123/jpah.2018-0240

Griffin, É. W., Mullally, S., Foley, C., Warmington, S. A., O’Mara, S. M., and Kelly, Á. M. (2011). Aerobic exercise improves hippocampal function and increases BDNF in the serum of young adult males. Physiol. Behav. 104, 934-941. doi: 10.1016/j.physbeh.2011.06.005

Grimbergen, Y. A. M., Munneke, M., and Bloem, B. R. (2004). Falls in Parkinson's disease. Curr. Opin. Neurol. 17, 405-415. doi: 10.1097/01.wco.0000137530.68867.93

Gustafsson, G., Lira, C. M., Johansson, J., Wisén, A., Wohlfart, B., Ekman, R., et al. (2009). The acute response of plasma brain-derived neurotrophic factor as a result of exercise in major depressive disorder. Psychiatry Res. 169, 244-248. doi: 10.1016/j.psychres.2008.06.030

Hallböök, F. (1999). Evolution of the vertebrate neurotrophin and Trk receptor gene families. Curr. Opin. Neurobiol. 9, 616-621. doi: 10.1016/S0959-4388(99)00011-2

Hauer, K., Schwenk, M., Zieschang, T., Essig, M., Becker, C., and Oster, P. (2012). Physical training improves motor performance in people with dementia: a randomized controlled trial. J. Am. Geriatr. Soc. 60, 8-15. doi: 10.1111/j.1532-5415.2011.03778.x

Heisz, J. J., Clark, I. B., Bonin, K., Paolucci, E. M., Michalski, B., Becker, S., et al. (2017). The effects of physical exercise and cognitive training on memory and neurotrophic factors. J. Cogn. Neurosci. 29, 1895-1907. doi: 10.1162/jocn_a_01164

Helm, E. E., Matt, K. S., Kirschner, K. F., Pohlig, R. T., Kohl, D., and Reisman, D. S. (2017). The influence of high intensity exercise and the Val66Met polymorphism on circulating BDNF and locomotor learning. Neurobiol. Learn. Mem. 144, 77-85. doi: 10.1016/j.nlm.2017.06.003

Hempstead, B. L. (2015). Brain-Derived neurotrophic factor: three ligands, many actions. Trans. Am. Clin. Clim. Assoc. 126, 9-19.

Herman, T., Giladi, N., Gruendlinger, L., and Hausdorff, J. M. (2007). Six weeks of intensive treadmill training improves gait and quality of life in patients with Parkinson's disease: a pilot study. Arch. Phys. Med. Rehabil. 88, 1154-1158. doi: 10.1016/j.apmr.2007.05.015

Heyman, E., Gamelin, F.-X., Goekint, M., Piscitelli, F., Roelands, B., Leclair, E., et al. (2012). Intense exercise increases circulating endocannabinoid and BDNF levels in humans-possible implications for reward and depression. Psychoneuroendocrinology 37, 844-851. doi: 10.1016/j.psyneuen.2011.09.017

Hirsch, M. A., Iyer, S. S., and Sanjak, M. (2016). Exercise-induced neuroplasticity in human Parkinson's disease: what is the evidence telling us? Park. Relat. Disord. 22, S78-S81. doi: 10.1016/j.parkreldis.2015.09.030

Hsu, C. L., Best, J. R., Wang, S., Voss, M. W., Hsiung, R. G. Y., Munkacsy, M., et al. (2017a). Corrigendum: the impact of aerobic exercise on fronto-parietal network connectivity and its relation to mobility: an exploratory analysis of a 6-month randomized controlled trial. Front. Hum. Neurosci. 11:449. doi: 10.3389/fnhum.2017.00449

Hsu, C. L., Best, J. R., Wang, S., Voss, M. W., Hsiung, R. G. Y., Munkacsy, M., et al. (2017b). The impact of aerobic exercise on fronto-parietal network connectivity and its relation to mobility: an exploratory analysis of a 6-month randomized controlled trial. Front. Hum. Neurosci. 11:344. doi: 10.3389/fnhum.2017. 00344 
Huang, E. J., and Reichardt, L. F. (2001). Neurotrophins: roles in neuronal development and function. Ann. Rev. Neurosci. 24, 677-736. doi: 10.1146/annurev.neuro.24.1.677

Huang, T., Larsen, K. T., Ried-Larsen, M., Møller, N. C., and Andersen, L. B. (2014). The effects of physical activity and exercise on brain-derived neurotrophic factor in healthy humans: a review. Scand. J. Med. Sci. Sport 24, 1-10. doi: 10.1111/sms.12069

Huang, Y., Huang, C., and Yun, W. (2019). Peripheral BDNF/TrkB protein expression is decreased in Parkinson's disease but not in essential tremor. J. Clin. Neurosci. 63, 176-181. doi: 10.1016/j.jocn.2019.01.017

Hübner, L., Godde, B., and Voelcker-Rehage, C. (2018). Acute exercise as an intervention to trigger motor performance and EEG Beta activity in older adults. Neural Plast. 2018:4756785. doi: 10.1155/2018/4756785

Illarioshkin, S. N., Klyushnikov, S. A., Vigont, V. A., Seliverstov, Y. A., and Kaznacheyeva, E. V (2018). Molecular pathogenesis in huntington's disease. Biochemistry 83, 1030-1039. doi: 10.1134/S0006297918090043

Inoue, T., Ninuma, S., Hayashi, M., Okuda, A., Asaka, T., and Maejima, H. (2018). Effects of long-term exercise and low-level inhibition of GABAergic synapses on motor control and the expression of BDNF in the motor related cortex. Neurol. Res. 40, 18-25. doi: 10.1080/01616412.2017.1382801

Ioannidis, G., Papaioannou, A., Hopman, W. M., Akhtar-Danesh, N., Anastassiades, T., Pickard, L., et al. (2009). Relation between fractures and mortality: results from the canadian multicentre osteoporosis study. CMAJ 181, 265-271. doi: 10.1503/cmaj.081720

Jamal, M., Does, W., Elzinga, B. M., Molendijk, M. L., and Penninx, B. W. J. H. (2015). Association between smoking, nicotine dependence, and BDNF Val66Met polymorphism with BDNF concentrations in serum. Nicotine Tob. Res. 17, 323-329. doi: 10.1093/ntr/ntu151

Jeon, Y. K., and Ha, C. H. (2017). The effect of exercise intensity on brain derived neurotrophic factor and memory in adolescents. Env. Health Prev. Med. 22:27. doi: 10.1186/s12199-017-0643-6

Jørgensen, L., Engstad, T., and Jacobsen, B. K. (2002). Higher incidence of falls in long-term stroke survivors than in population controls: depressive symptoms predict falls after stroke. Stroke 33, 542-547. doi: 10.1161/hs0202.102375

Karege, F., Schwald, M., and Cisse, M. (2002). Postnatal developmental profile of brain-derived neurotrophic factor in rat brain and platelets. Neurosci. Lett. 328, 261-264. doi: 10.1016/S0304-3940(02)00529-3

Kerschensteiner, M., Gallmeier, E., Behrens, L., Leal, V. V, Misgeld, T., Klinkert, W. E., et al. (1999). Activated human T cells, B cells, and monocytes produce brain-derived neurotrophic factor in vitro and in inflammatory brain lesions: a neuroprotective role of inflammation? J. Exp. Med. 189, 865-870. doi: 10.1084 /jem.189.5.865

Kleim, J. A., Chan, S., Pringle, E., Schallert, K., Procaccio, V., Jimenez, R., et al. (2006). BDNF val66met polymorphism is associated with modified experiencedependent plasticity in human motor cortex. Nat. Neurosci. 9, 735-737. doi: $10.1038 / \mathrm{nn} 1699$

Klein, A. B., Williamson, R., Santini, M. A., Clemmensen, C., Ettrup, A., Rios, M., et al. (2011). Blood BDNF concentrations reflect brain-tissue BDNF levels across species. Int. J. Neuropsychopharmacol. 14, 347-353. doi: $10.1017 /$ S1461145710000738

Knaepen, K., Goekint, M., Heyman, E. M., and Meeusen, R. (2010). Neuroplasticity - exercise-induced response of peripheral brain-derived neurotrophic factor: a systematic review of experimental studies in human subjects. Sport Med. 40, 765-801. doi: 10.2165/11534530-000000000-00000

Koshimizu, H., Kiyosue, K., Hara, T., Hazama, S., Suzuki, S., Uegaki, K., et al. (2009). Multiple functions of precursor BDNF to CNS neurons: negative regulation of neurite growth, spine formation and cell survival. Mol. Brain 2:27. doi: 10.1186/1756-6606-2-27

Kowiański, P., Lietzau, G., Czuba, E., Waśkow, M., Steliga, A., and Moryś, J. (2018). BDNF: a key factor with multipotent impact on brain signaling and synaptic plasticity. Cell. Mol. Neurobiol. 38, 579-593. doi: 10.1007/s10571-017-0510-4

Krabbe, K. S., Nielsen, A. R., Krogh-Madsen, R., Plomgaard, P., Rasmussen, P., Erikstrup, C., et al. (2007). Brain-derived neurotrophic factor (BDNF) and type 2 diabetes. Daibetologia 50, 431-438. doi: 10.1007/s00125-0060537-4

Kuipers, S. D., and Bramham, C. R. (2006). Brain-derived neurotrophic factor mechanisms and function in adult synaptic plasticity: new insights and implications for therapy. Curr. Opin. Drug Discov. Dev. 9, 580-586.
Lach, H. W., Harrison, B. E., and Phongphanngam, S. (2017). Falls and fall prevention in older adults with early-stage dementia: an integrative review. Res Gerontol. Nurs. 10, 139-148. doi: 10.3928/19404921-20160908-01

Laske, C., Banschbach, S., Stransky, E., Bosch, S., Straten, G., Machann, J., et al. (2010). Exercise-induced normalization of decreased BDNF serum concentration in elderly women with remitted major depression. Int. J. Neuropsychopharmacol. 13, 595-602. doi: 10.1017/S1461145709991234

Leal, G., Bramham, C. R., and Duarte, C. B. (2017). BDNF and hippocampal synaptic plasticity. Vitam. Horm. 104, 153-195. doi: 10.1016/bs.vh.2016.10.004

Leal, G., Comprido, D., and Duarte, C. B. (2014). BDNF-induced local protein synthesis and synaptic plasticity. Neuropharmacology 76 (Pt. C), 639-656. doi: 10.1016/j.neuropharm.2013.04.005

Leckie, R. L., Oberlin, L. E., Voss, M. W., Prakash, R. S., Szabo-Reed, A., ChaddockHeyman, L., et al. (2014). BDNF mediates improvements in executive function following a 1-year exercise intervention. Front. Hum. Neurosci. 8:985. doi: $10.3389 /$ fnhum.2014.00985

Lee, R., Kermani, P., Teng, K. K., and Hempstead, B. L. (2001). Regulation of cell survival by secreted proneurotrophins. Science 294, 1945-1948. doi: 10.1126/science.1065057

Lehmann, N., Villringer, A., and Taubert, M. (2020). Colocalized white matter plasticity and increased cerebral blood flow mediate the beneficial effect of cardiovascular exercise on long-term motor learning. J. Neurosci. 40, 2416-2429. doi: 10.1523/JNEUROSCI.2310-19.2020

Leventhal, C., Rafii, S., Rafii, D., Shahar, A., and Goldman, S. A. (1999). Endothelial trophic support of neuronal production and recruitment from the adult mammalian subependyma. Mol. Cell Neurosci. 13, 450-464. doi: $10.1006 /$ mcne. 1999.0762

Levinger, I., Goodman, C., Matthews, V., Hare, D. L., Jerums, G., Garnham, A., et al. (2008). BDNF, metabolic risk factors, and resistance training in middle-aged individuals. Med. Sci. Sport Exerc. 40, 535-541. doi: 10.1249/MSS.0b013e31815dd057

Lewin, G. R., and Barde, Y. A. (1996). Physiology of the neurotrophins. Annu. Rev. Neurosci. 19, 289-317. doi: 10.1146/annurev.ne.19.030196.001445

Lima Giacobbo, B., Doorduin, J., Klein, H. C., Dierckx, R. A. J. O., Bromberg, E., and Vries, E. F. J. (2019). Brain-Derived neurotrophic factor in brain disorders: focus on neuroinflammation. Mol. Neurobiol. 56, 3295-3312. doi: 10.1007/s12035-018-1283-6

Linder, S. M., Rosenfeldt, A. B., Davidson, S., Zimmerman, N., Penko, A., Lee, J., et al. (2019). Forced, not voluntary, aerobic exercise enhances motor recovery in persons with chronic stroke. Neurorehabil. Neural Repair 33, 681-690. doi: $10.1177 / 1545968319862557$

Liu-Ambrose, T., Donaldson, M. G., Ahamed, Y., Graf, P., Cook, W. L., Close, J., et al. (2008). Otago home-based strength and balance retraining improves executive functioning in older fallers: a randomized controlled trial. J. Am. Geriatr. Soc. 56, 1821-1830. doi: 10.1111/j.1532-5415.2008.01931.x

Liu-Ambrose, T., Nagamatsu, L. S., Hsu, C. L., and Bolandzadeh, N. (2013). Emerging concept: "central benefit model" of exercise in falls prevention. $\mathrm{Br}$. J. Sport Med. 47, 115-117. doi: 10.1136/bjsports-2011-090725

Lommatzsch, M., Zingler, D., Schuhbaeck, K., Schloetcke, K., Zingler, C., Schuff-Werner, P., et al. (2005). The impact of age, weight and gender on BDNF levels in human platelets and plasma. Neurobiol. Aging 26, 115-123. doi: 10.1016/j.neurobiolaging.2004.03.002

Lu, B., Nagappan, G., and Lu, Y. (2014). BDNF and synaptic plasticity, cognitive function, and dysfunction. Handb. Exp. Pharmacol. 220, 223-250. doi: 10.1007/978-3-642-45106-5_9

Lu, B., Pang, P. T., and Woo, N. H. (2005). The yin and yang of neurotrophin action. Nat. Rev. Neurosci. 6, 603-614. doi: 10.1038/nrn1726

Maass, A., Düzel, S., Brigadski, T., Goerke, M., Becke, A., Sobieray, U., et al. (2016). Relationships of peripheral IGF-1, VEGF and BDNF levels to exercise-related changes in memory, hippocampal perfusion and volumes in older adults. Neuroimage 131, 142-154. doi: 10.1016/j.neuroimage.2015.10.084

Mackay, C. P., Kuys, S. S., and Brauer, S. G. (2017). The effect of aerobic exercise on brain-derived neurotrophic factor in people with neurological disorders: a systematic review and meta-analysis. Neural Plast. 2017:4716197. doi: $10.1155 / 2017 / 4716197$

Maffioletti, E., Zanardini, R., Gennarelli, M., and Bocchio-Chiavetto, L. (2014). Influence of clotting duration on brain-derived neurotrophic factor (BDNF) dosage in serum. Biotechniques 57, 111-114. doi: 10.2144/000114204 
Mang, C. S., Campbell, K. L., Ross, C. J. D., and Boyd, L. A. (2013). Promoting neuroplasticity for motor rehabilitation after stroke: considering the effects of aerobic exercise and genetic variation on brain-derived neurotrophic factor. Phys. Ther. 93, 1707-1716. doi: 10.2522/ptj.20130053

Mang, C. S., McEwen, L. M., MacIsaac, J. L., Snow, N. J., Campbell, K. L., Kobor, M. S., et al. (2017). Exploring genetic influences underlying acute aerobic exercise effects on motor learning. Sci. Rep. 7:12123. doi: 10.1038/s41598-017-12422-3

Mang, C. S., Snow, N. J., Campbell, K. L., Ross, C. J. D., and Boyd, L. A. (2014). A single bout of high-intensity aerobic exercise facilitates response to paired associative stimulation and promotes sequence-specific implicit motor learning. J. Appl. Physiol. 117, 1325-1336. doi: 10.1152/japplphysiol.00498.2014

Marigold, D. S., Eng, J. J., Dawson, A. S., Inglis, J. T., Harris, J. E., and Gylfadóttir, S. (2005). Exercise leads to faster postural reflexes, improved balance and mobility, and fewer falls in older persons with chronic stroke. J. Am. Geriatr. Soc. 53, 416-423. doi: 10.1111/j.1532-5415.2005.53158.x

Marinus, N., Hansen, D., Feys, P., Meesen, R., Timmermans, A., and Spildooren, J. (2019). The impact of different types of exercise training on peripheral blood brain-derived neurotrophic factor concentrations in older adults: a meta-analysis. Sport. Med. 49, 1529-1546. doi: 10.1007/s40279-019-01148-z

Marston, K. J., Newton, M. J., Brown, B. M., Rainey-Smith, S. R., Bird, S., Martins, R. N., et al. (2017). Intense resistance exercise increases peripheral brain-derived neurotrophic factor. J. Sci. Med. Sport 20, 899-903. doi: 10.1016/j.jsams.2017.03.015

McAllister, A. K. (2002). Neurotrophins and cortical development. Results Probl. Cell Differ. 39:112. doi: 10.1007/978-3-540-46006-0_5

McAllister, A. K., Katz, L. C., and Lo, D. C. (1999). Neurotrophins and synaptic plasticity. Annu. Rev. Neurosci. 22, 295-318. doi: 10.1146/annurev.neuro.22.1.295

McAllister, A. K., Lo, D. C., and Katz, L. C. (1995). Neurotrophins regulate dendritic growth in developing visual cortex. Neuron 15, 791-803. doi: 10.1016/0896-6273(95)90171-X

McConnell, M. J., Huang, Y. H., Datwani, A., and Shatz, C. J. (2009). H2-K(b) and $\mathrm{H} 2-\mathrm{D}$ (b) regulate cerebellar long-term depression and limit motor learning. Proc. Natl. Acad. Sci. U.S.A. 106, 6784-6789. doi: 10.1073/pnas.0902018106

McDonnell, M. N., Buckley, J. D., Opie, G. M., Ridding, M. C., and Semmler, J. G. (2013). A single bout of aerobic exercise promotes motor cortical neuroplasticity. J. Appl. Physiol. 114, 1174-1182. doi: 10.1152/japplphysiol.01378.2012

Means, K. M., Rodell, D. E., and O'Sullivan, P. S. (2005). Balance, mobility, and falls among community-dwelling elderly persons: effects of a rehabilitation exercise program. Am. J. Phys. Med. Rehabil. 84, 238-250. doi: 10.1097/01.PHM.0000151944.22116.5A

Mehrholz, J., Kugler, J., Storch, A., Pohl, M., Hirsch, K., and Elsner, B. (2015). Treadmill training for patients with Parkinson's disease. Cochrane Database Syst. Rev. 9:CD007830. doi: 10.1002/14651858.CD007830.pub3

Mohammadi, A., Amooeian, V. G., and Rashidi, E. (2018). Dysfunction in brain-derived neurotrophic factor signaling pathway and susceptibility to schizophrenia, Parkinson's and Alzheimer's diseases. Curr. Gene Ther. 18, 45-63. doi: 10.2174/1566523218666180302163029

Molendijk, M. L., Spinhoven, P., Polak, M., Bus, B. A. A., Penninx, B. W. J. H., and Elzinga, B. M. (2014). Serum BDNF concentrations as peripheral manifestations of depression: evidence from a systematic review and meta-analyses on 179 associations $(\mathrm{N}=9484)$. Mol. Psychiatry 19, 791-800. doi: $10.1038 / \mathrm{mp} .2013 .105$

Monfils, M.-H., Plautz, E. J., and Kleim, J. A. (2005). In search of the motor engram: motor map plasticity as a mechanism for encoding motor experience. Neuroscientist 11, 471-483. doi: 10.1177/1073858405278015

Mowla, S. J., Farhadi, H. F., Pareek, S., Atwal, J. K., Morris, S. J., Seidah, N. G., et al. (2001). Biosynthesis and post-translational processing of the precursor to brain-derived neurotrophic factor. J. Biol. Chem. 276, 12660-12666. doi: 10.1074/jbc.M008104200

Muellbacher, W., Ziemann, U., Wissel, J., Dang, N., Kofler, M., Facchini, S., et al. (2002). Early consolidation in human primary motor cortex. Nature 415, 640-644. doi: 10.1038/nature712

Naegelin, Y., Dingsdale, H., Säuberli, K., Schädelin, S., Kappos, L., and Barde, Y.-A. (2018). Measuring and validating the levels of brainderived neurotrophic factor in human serum. eNeuro 5:e0419-17; 1-9. doi: 10.1523/ENEURO.0419-17.2018
Nakahashi, T., Fujimura, H., Altar, C. A., Li, J., Kambayashi, J., Tandon, N. N., et al. (2000). Vascular endothelial cells synthesize and secrete brain-derived neurotrophic factor. FEBS Lett. 470, 113-117. doi: 10.1016/S0014-5793(00)01302-8

Nepveu, J.-F., Thiel, A., Tang, A., Fung, J., Lundbye-Jensen, J., Boyd, L. A., et al. (2017). A single bout of high-intensity interval training improves motor skill retention in individuals with stroke. Neurorehabil. Neural Repair 31, 726-735. doi: $10.1177 / 1545968317718269$

Ng, T. K. S., Ho, C. S. H., Tam, W. W. S., Kua, E. H., and Ho, R. C.-M. (2019). Decreased serum brain-derived neurotrophic factor (BDNF) levels in patients with Alzheimer's disease (AD): a systematic review and meta-analysis. Int. J. Mol. Sci. 20:257. doi: 10.3390/ijms20020257

Nicolini, C., Michalski, B., Toepp, S. L., Turco, C. V, D’Hoine, T., Harasym, D., et al. (2020). A single bout of high-intensity interval exercise increases corticospinal excitability, brain-derived neurotrophic factor and uncarboxylated osteolcalcin in sedentary, healthy males. Neuroscience. 437:242-255. doi: 10.1016/j.neuroscience.2020.03.042

Nicolini, C., Toepp, S., Harasym, D., Michalski, B., Fahnestock, M., Gibala, M. J., et al. (2019). No changes in corticospinal excitability, biochemical markers, and working memory after six weeks of high-intensity interval training in sedentary males. Physiol. Rep. 7:e14140. doi: 10.14814/phy2.14140

Numakawa, T., Odaka, H., and Adachi, N. (2018). Actions of brain-derived neurotrophin factor in the neurogenesis and neuronal function, and its involvement in the pathophysiology of brain diseases. Int. J. Mol. Sci. 19:3650. doi: 10.3390/ijms19113650

Osoba, M. Y., Rao, A. K., Agrawal, S. K., and Lalwani, A. K. (2019). Balance and gait in the elderly: a contemporary review. Laryngosc. Investig. Otolaryngol. 4, 143-153. doi: 10.1002/lio2.252

Ostadan, F., Centeno, C., Daloze, J.-F., Frenn, M., Lundbye-Jensen, J., and Roig, M. (2016). Changes in corticospinal excitability during consolidation predict acute exercise-induced off-line gains in procedural memory. Neurobiol. Learn. Mem. 136, 196-203. doi: 10.1016/j.nlm.2016.10.009

Overstall, P., Exton-Smith, A., Imms, F., and Johnson, A. (1977). Falls in the elderly related to postural imbalance. Br. Med. J. 1, 261-264. doi: 10.1136/bmj.1.6056.261

Pahor, M., Guralnik, J. M., Ambrosius, W. T., Blair, S., Bonds, D. E., Church, T. S., et al. (2014). Effect of structured physical activity on prevention of major mobility disability in older adults: the LIFE study randomized clinical trial. JAMA 311, 2387-2396. doi: 10.1001/jama.2014.5616

Pan, W., Banks, W. A., Fasold, M. B., Bluth, J., and Kastin, A. J. (1998). Transport of brain-derived neurotrophic factor across the blood-brain barrier. Neuropharmacology 37, 1553-1561. doi: 10.1016/S0028-3908(98) 00141-5

Pang, P. T., Nagappan, G., Guo, W., and Lu, B. (2016). Extracellular and intracellular cleavages of proBDNF required at two distinct stages of late-phase LTP. NPJ Sci. Learn. 1:16003. doi: 10.1038/npjscilearn.2016.3

Pang, P. T., Teng, H. K., Zaitsev, E., Woo, N. T., Sakata, K., Zhen, S., et al. (2004). Cleavage of proBDNF by tPA/plasmin is essential for long-term hippocampal plasticity. Science 306, 487-491. doi: 10.1126/science.1100135

Park, H., and Poo, M. (2013). Neurotrophin regulation of neural circuit development and function. Nat. Rev. Neurosci. 14, 7-23. doi: 10.1038/nrn3379

Pereira, D. S., de Queiroz, B. Z., Miranda, A. S., Rocha, N. P., Felício, D. C., Mateo, E. C., et al. (2013). Effects of physical exercise on plasma levels of brain-derived neurotrophic factor and depressive symptoms in elderly women-a randomized clinical trial. Arch. Phys. Med. Rehabil. 94, 1443-1450. doi: 10.1016/j.apmr.2013.03.029

Perrey, S. (2013). Promoting motor function by exercising the brain. Brain Sci. 3, 101-122. doi: 10.3390/brainsci3010101

Petzinger, G. M., Fisher, B. E., McEwen, S., Beeler, J. A., Walsh, J. P., and Jakowec, M. W. (2013). Exercise-enhanced neuroplasticity targeting motor and cognitive circuitry in Parkinson's disease. Lancet Neurol. 12, 716-726. doi: 10.1016/S1474-4422(13)70123-6

Petzinger, G. M., Fisher, B. E., Van Leeuwen, J. E., Vukovic, M., Akopian, G., Meshul, C. K., et al. (2010). Enhancing neuroplasticity in the basal ganglia: the role of exercise in Parkinson's disease. Mov. Disord. 25, S141-S145. doi: $10.1002 / \mathrm{mds} .22782$

Piccinni, A., Marazziti, D., Debbio, A., Bianchi, C., Roncaglia, I., Mannari, C., et al. (2008). Diurnal variation of plasma brain-derived neurotrophic factor 
(BDNF) in humans: an analysis of sex differences. Chronobiol. Int. 25, 819-826. doi: 10.1080/07420520802387773

Pitkälä, K., Savikko, N., Poysti, M., Strandberg, T., and Laakkonen, M. L. (2013). Efficacy of physical exercise intervention on mobility and physical functioning in older people with dementia: a systematic review. Exp. Gerontol. 48, 85-93. doi: 10.1016/j.exger.2012.08.008

Pluchino, N., Cubeddu, A., Begliuomini, S., Merlini, S., Giannini, A., Bucci, F., et al. (2009). Daily variation of brain-derived neurotrophic factor and cortisol in women with normal menstrual cycles, undergoing oral contraception and in postmenopause. Hum. Reprod. 24, 2303-2309. doi: 10.1093/humrep/dep119

Poduslo, J. F., and Curran, G. L. (1996). Permeability at the blood-brain and bloodnerve barriers of the neurotrophic factors: NGF, CNTF, NT-3, BDNF. Brain Res. Mol. Brain Res. 36, 280-286. doi: 10.1016/0169-328X(95)00250-V

Polacchini, A., Metelli, G., Francavilla, R., Baj, G., Florean, M., Mascaretti, L. G., et al. (2015). A method for reproducible measurements of serum BDNF: comparison of the performance of six commercial assays. Sci. Rep. 5:17989. doi: 10.1038/srep17989

Polyakova, M., Schlögl, H., Sacher, J., Schmidt-Kassow, M., Kaiser, J., Stumvoll, M., et al. (2017). Stability of BDNF in human samples stored up to 6 months and correlations of serum and EDTA-plasma concentrations. Int. J. Mol. Sci. 18:1189. doi: $10.3390 /$ ijms 18061189

Poo, M. M. (2001). Neurotrophins as synaptic modulators. Nat. Rev. Neurosci. 2, 24-32. doi: 10.1038/35049004

Pruunsild, P., Kazantseva, A., Aid, T., Palm, K., and Timmusk, T. (2007). Dissecting the human BDNF locus: bidirectional transcription, complex splicing, and multiple promoters. Genomics 90, 397-406. doi: 10.1016/j.ygeno.2007.05.004

Quaney, B. M., Boyd, L. A., McDowd, J. M., Zahner, L. H., Jianghua He, Mayo, M. S., et al. (2009). Aerobic exercise improves cognition and motor function poststroke. Neurorehabil. Neural Repair 23, 879-885. doi: $10.1177 / 1545968309338193$

Radka, S. F., Holst, P. A., Fritsche, M., and Altar, C. A. (1996). Presence of brainderived neurotrophic factor in brain and human and rat but not mouse serum detected by a sensitive and specific immunoassay. Brain Res. 709, 122-301. doi: 10.1016/0006-8993(95)01321-0

Rasmussen, P., Brassard, P., Adser, H., Pedersen, M. V., Leick, L., Hart, E., et al. (2009). Evidence for a release of brain-derived neurotrophic factor from the brain during exercise. Exp. Physiol. 94, 1062-1069. doi: 10.1113/expphysiol.2009.048512

Ridgel, A. L., Vitek, J. L., and Alberts, J. L. (2009). Forced, not voluntary, exercise improves motor function in Parkinson's disease patients. Neurorehabil. Neural Repair 23, 600-608. doi: 10.1177/1545968308328726

Rikli, R. E., and Edwards, D. J. (1991). Effects of a three-year exercise program on motor function and cognitive processing speed in older women. Res. Q. Exerc. Sport 62, 61-67. doi: 10.1080/02701367.1991.10607519

Rioult-Pedotti, M. S., Friedman, D., and Donoghue, J. P. (2000). Learning-induced LTP in neocortex. Science 290, 533-536. doi: 10.1126/science.290.5491.533

Robertson, M. C., Campbell, A. J., Gardner, M. M., and Devlin, N. (2002). Preventing injuries in older people by preventing falls: a metaanalysis of individual-level data. J. Am. Geriatr. Soc. 50, 905-911. doi: 10.1046/j.1532-5415.2002.50218.x

Rojas Vega, S., Kleinert, J., Sulprizio, M., Hollmann, W., Bloch, W., and Strüder, H. K. (2011). Responses of serum neurotrophic factors to exercise in pregnant and postpartum women. Psychoneuroendocrinology 36, 220-227. doi: 10.1016/j.psyneuen.2010.07.012

Rosenfeld, R. D., Zeni, L., Haniu, M., Talvenheimo, J., Radka, S. F., Bennett, L., et al. (1995). Purification and identification of brain-derived neurotrophic factor from human serum. Protein Expr. Puriff. 6, 465-471. doi: 10.1006/prep.1995.1062

Rossini, P. M., Burke, D., Chen, R., Cohen, L. G., Daskalakis, Z., Di Iorio, R., et al. (2015). Non-invasive electrical and magnetic stimulation of the brain, spinal cord, roots and peripheral nerves: basic principles and procedures for routine clinical and research application: an updated report from an I.F.C.N. committee. Clin. Neurophysiol. 126, 1071-1107. doi: 10.1016/j.clinph.2015.02.001

Ruscheweyh, R., Willemer, C., Krüger, K., Duning, T., Warnecke, T., Sommer, J., et al. (2011). Physical activity and memory functions: an interventional study. Neurobiol. Aging 32, 1304-1319. doi: 10.1016/j.neurobiolaging.2009.08.001
Sartorius, A., Hellweg, R., Litzke, J., Vogt, M., Dormann, C., Vollmayr, B., et al. (2009). Correlations and discrepancies between serum and brain tissue levels of neurotrophins after electroconvulsive treatment in rats. Pharmacopsychiatry 42, 270-276. doi: 10.1055/s-0029-1224162

Saucedo Marquez, C. M., Vanaudenaerde, B., Troosters, T., and Wenderoth, N. (2015). High-intensity interval training evokes larger serum BDNF levels compared with intense continuous exercise. J. Appl. Physiol. 119, 1363-1373. doi: 10.1152/japplphysiol.00126.2015

Schiffer, T., Schulte, S., Hollmann, W., Bloch, W., and Strüder, H. (2009). Effects of strength and endurance training on brain-derived neurotrophic factor and insulin-like growth factor 1 in humans. Horm. Metab. Res. 41, 250-254. doi: $10.1055 / \mathrm{s}-0028-1093322$

Schinder, A. F., and Poo, M. (2000). The neurotrophin hypothesis for synaptic plasticity. Trends Neurosci. 23, 639-645. doi: 10.1016/S0166-2236(00)01672-6

Schmidt-Kassow, M., Schädle, S., Otterbein, S., Thiel, C., Doehring, A., Lötsch, J., et al. (2012). Kinetics of serum brain-derived neurotrophic factor following low-intensity versus high-intensity exercise in men and women. Neuroreport 23, 889-893. doi: 10.1097/WNR.0b013e32835946ca

Schmolesky, M. T., Webb, D. L., and Hansen, R. A. (2013). The effects of aerobic exercise intensity and duration on levels of brain-derived neurotrophic factor in healthy men. J. Sports Sci. Med. 12, 502-511.

Schulz, K.-H., Gold, S. M., Witte, J., Bartsch, K., Lang, U. E., Hellweg, R., et al. (2004). Impact of aerobic training on immune-endocrine parameters, neurotrophic factors, quality of life and coordinative function in multiple sclerosis. J. Neurol Sci. 225, 11-18. doi: 10.1016/j.jns.2004.06.009

Schwenk, M., Dutzi, I., Englert, S., Micol, W., Najafi, B., Mohler, J., et al. (2014a). An intensive exercise program improves motor performances in patients with dementia: translational model of geriatric rehabilitation. J. Alzheimers Dis. 39, 487-498. doi: 10.3233/JAD-130470

Schwenk, M., Zieschang, T., Englert, S., Grewal, G., Najafi, B., and Hauer, K. (2014b). Improvements in gait characteristics after intensive resistance and functional training in people with dementia: a randomised controlled trial. BMC Geriatr. 14:73. doi: 10.1186/1471-2318-14-73

Seidah, N. G., Benjannet, S., Pareek, S., Chrétien, M., and Murphy, R. A. (1996). Cellular processing of the neurotrophin precursors of NT3 and BDNF by the mammalian proprotein convertases. FEBS Lett. 379, 247-250. doi: 10.1016/0014-5793(95)01520-5

Seidah, N. G., Mowla, S. J., Hamelin, J., Mamarbachi, A. M., Benjannet, S., Touré, B. B., et al. (1999). Mammalian subtilisin/kexin isozyme SKI1: a widely expressed proprotein convertase with a unique cleavage specificity and cellular localization. Proc Natl Acad Sci USA 96, 1321-1326. doi: 10.1073/pnas.96.4.1321

Seifert, T., Brassard, P., Wissenberg, M., Rasmussen, P., Nordby, P., Stallknecht, B., et al. (2010). Endurance training enhances BDNF release from the human brain. Am. J. Physiol. Regul. Integr. Comp. Physiol. 298, R372-R377. doi: 10.1152/ajpregu.00525.2009

Sen, S., Duman, R., and Sanacora, G. (2008). Serum brain-derived neurotrophic factor, depression, and antidepressant medications: meta-analyses and implications. Biol. Psychiatry 64, 527-532. doi: 10.1016/j.biopsych.2008.05.005

Serra-Millàs, M. (2016). Are the changes in the peripheral brain-derived neurotrophic factor levels due to platelet activation? World J. Psychiatry 6, 84-101. doi: 10.5498/wjp.v6.i1.84

Shepherd, R. B. (2001). Exercise and training to optimize functional motor performance in stroke: driving neural reorganization? Neural Plast. 8, 121-129. doi: 10.1155/NP.2001.121

Singh, A. M., Neva, J. L., and Staines, W. R. (2014). Acute exercise enhances the response to paired associative stimulation-induced plasticity in the primary motor cortex. Exp. Brain Res. 232, 3675-3685. doi: 10.1007/s00221-014-4049-Z

Skriver, K., Roig, M., Lundbye-Jensen, J., Pingel, J., Helge, J. W., Kiens, B., et al. (2014). Acute exercise improves motor memory: exploring potential biomarkers. Neurobiol. Learn. Mem. 116, 46-58. doi: 10.1016/j.nlm.2014.08.004

Stavrinos, E. L., and Coxon, J. P. (2017). High-intensity interval exercise promotes motor cortex disinhibition and early motor skill consolidation. J. Cogn. Neurosci. 29, 593-604. doi: 10.1162/jocn_a_01078

Steib, S., Wanner, P., Adler, W., Winkler, J., Klucken, J., and Pfeifer, K. (2018). A single bout of aerobic exercise improves motor skill consolidation in Parkinson's disease. Front. Aging Neurosci. 10:328. doi: $10.3389 /$ fnagi.2018.00328 
Stein, J. (2004). Motor recovery strategies after stroke. Top Stroke Rehabil. 11, 12-22. doi: 10.1310/RK4A-6ETG-K8RL-3XA7

Sterling, D. A., O'Connor, J. A., and Bonadies, J. (2001). Geriatric falls: Injury severity is high and disproportionate to mechanism. J. Trauma Inj. Infect. Crit. Care 50, 116-119. doi: 10.1097/00005373-200101000-00021

Stoll, P., Plessow, A., Bratke, K., Virchow, J. C., and Lommatzsch, M. (2011). Differential effect of clopidogrel and aspirin on the release of BDNF from platelets. J. Neuroimmunol 238, 104-106. doi: 10.1016/j.jneuroim.2011.06.015

Suliman, S., Hemmings, S. M. J., and Seedat, S. (2013). Brain-Derived Neurotrophic Factor (BDNF) protein levels in anxiety disorders: systematic review and meta-regression analysis. Front. Integr. Neurosci. 7:55. doi: 10.3389/fnint.2013.00055

Szuhany, K. L., Bugatti, M., and Otto, M. W. (2015). A meta-analytic review of the effects of exercise on brain-derived neurotrophic factor. J Psychiatr Res 60, 56-64. doi: 10.1016/j.jpsychires.2014.10.003

Tang, S. W., Chu, E., Hui, T., Helmeste, D., and Law, C. (2008). Influence of exercise on serum brain-derived neurotrophic factor concentrations in healthy human subjects. Neurosci. Lett. 431, 62-65. doi: 10.1016/j.neulet.2007.11.019

Teng, H. K., Teng, K. K., Lee, R., Wright, S., Tevar, S., Almeida, R. D., et al. (2005). ProBDNF induces neuronal apoptosis via activation of a receptor complex of p75NTR and sortilin. J. Neurosci. 25, 5455-5463. doi: 10.1523/JNEUROSCI.5123-04.2005

Tinetti, M., and Williams, C. (1998). The effect of falls and fall injuries on functioning in community-dwelling older persons. J. Gerontol. A Biol. Sci. Med. Sci. 53, M112-9. doi: 10.1093/gerona/53A.2.M112

Tinetti, M. E., and Kumar, C. (2010). The patient who falls: "It's always a trade-off." JAMA - J. Am. Med. Assoc. 303, 258-266. doi: 10.1001/jama.2009.2024

Todd, C., and Skelton, D. (2004). What are the Main Risk Factors for Falls Among Older People and What Are the Most Effective Interventions to Prevent These Falls? Copenhagen: World Health Organization Regional Office for Europe.

Trajkovska, V., Marcussen, A. B., Vinberg, M., Hartvig, P., Aznar, S., and Knudsen, G. M. (2007). Measurements of brain-derived neurotrophic factor: methodological aspects and demographical data. Brain Res. Bull. 73, 143-149. doi: 10.1016/j.brainresbull.2007.03.009

Tsuchimine, S., Sugawara, N., Ishioka, M., and Yasui-Furukori, N. (2014). Preanalysis storage conditions influence the measurement of brain-derived neurotrophic factor levels in peripheral blood. Neuropsychobiology 69, 83-88. doi: $10.1159 / 000358061$

Tyler, W. J., Alonso, M., Bramham, C. R., and Pozzo-Miller, L. D. (2002). From acquisition to consolidation: on the role of brain-derived neurotrophic factor signaling in hippocampal-dependent learning. Learn. Mem. 9, 224-237. doi: $10.1101 / \mathrm{lm} .51202$

van der Kolk, N. M., and King, L. A. (2013). Effects of exercise on mobility in people with Parkinson's disease. Mov. Disord. 28, 1587-1596. doi: 10.1002/mds.25658

Visser, M., Pluijm, S. M. F., Stel, V. S., Bosscher, R. J., and Deeg, D. J. H. (2002). Physical activity as a determinant of change in mobility performance: the longitudinal aging study Amsterdam. J. Am. Geriatr. Soc. 50, 1774-1781. doi: 10.1046/j.1532-5415.2002.50504.x

Voss, M. W., Erickson, K. I., Prakash, R. S., Chaddock, L., Kim, J. S., Alves, H., et al. (2013a). Neurobiological markers of exercise-related brain plasticity in older adults. Brain. Behav. Immun. 28, 90-99. doi: 10.1016/j.bbi.2012.10.021

Voss, M. W., Heo, S., Prakash, R. S., Erickson, K. I., Alves, H., Chaddock, L., et al. (2013b). The influence of aerobic fitness on cerebral white matter integrity and cognitive function in older adults: results of a one-year exercise intervention. Hum. Brain Mapp. 34, 2972-2985. doi: 10.1002/hbm.22119

Vreugdenhil, A., Cannell, J., Davies, A., and Razay, G. (2012). A communitybased exercise programme to improve functional ability in people with Alzheimer's disease: a randomized controlled trial. Scand. J. Caring Sci. 26, 12-19. doi: 10.1111/j.1471-6712.2011.00895.x
Waterhouse, E. G., and Xu, B. (2009). New insights into the role of brain-derived neurotrophic factor in synaptic plasticity. Mol. Cell. Neurosci. 42, 81-89. doi: 10.1016/j.mcn.2009.06.009

Weerdesteyn, V., de Niet, M., van Duijnhoven, H. J. R., and Geurts, A. C. H. (2008). Falls in individuals with stroke. J. Rehabil. Res. Dev. 45, 1195-1213. doi: 10.1682/JRRD.2007.09.0145

Winter, B., Breitenstein, C., Mooren, F. C., Voelker, K., Fobker, M., Lechtermann, A., et al. (2007). High impact running improves learning. Neurobiol. Learn. Mem. 87, 597-609. doi: 10.1016/j.nlm.2006.11.003

Winter, D., Patla, A., Frank, J., and Walt, S. (1990). Biomechanical walking pattern changes in the fit and healthy elderly. Phys. Ther. 70, 340-347. doi: 10.1093/ptj/70.6.340

Woo, N. H., Teng, H. K., Siao, C.-J., Chiaruttini, C., Pang, P. T., Milner, T. A., et al. (2005). Activation of p75NTR by proBDNF facilitates hippocampal long-term depression. Nat. Neurosci. 8, 1069-1077. doi: 10.1038/nn1510

Xu, T., Clemson, L., O'Loughlin, K., Lannin, N. A., Dean, C., and Koh, G. (2018). Risk factors for falls in community stroke survivors: a systematic review and meta-analysis. Arch. Phys. Med. Rehabil. 99, 563-573. doi: 10.1016/j.apmr.2017.06.032

Yamamoto, H., and Gurney, M. E. (1990). Human platelets contain brain-derived neurotrophic factor. J. Neurosci. 10, 3469-3478. doi: 10.1523/JNEUROSCI.10-11-03469.1990

Yarrow, J. F., White, L. J., McCoy, S. C., and Borst, S. E. (2010). Training augments resistance exercise induced elevation of circulating brain derived neurotrophic factor (BDNF). Neurosci. Lett. 479, 161-165. doi: 10.1016/j.neulet.2010. 05.058

Yoshii, A., and Constantine-Paton, M. (2010). Postsynaptic BDNF-TrkB signaling in synapse maturation, plasticity, and disease. Dev. Neurobiol. 70, 304-322. doi: $10.1002 /$ dneu.20765

Zhang, W., Low, L.-F., Schwenk, M., Mills, N., Gwynn, J. D., and Clemson, L. (2019). Review of gait, cognition, and fall risks with implications for fall prevention in older adults with dementia. Dement. Geriatr. Cogn. Disord. 48, 17-29. doi: 10.1159/000504340

Ziegenhorn, A. A., Schulte-Herbrüggen, O., Danker-Hopfe, H., Malbranc, M., Hartung, H.-D., Anders, D., et al. (2007). Serum neurotrophinsa study on the time course and influencing factors in a large old age sample. Neurobiol. Aging 28, 1436-1445. doi: 10.1016/j.neurobiolaging.2006. 06.011

Ziemann, U., Reis, J., Schwenkreis, P., Rosanova, M., Strafella, A., Badawy, R., et al. (2015). TMS and drugs revisited 2014. Clin. Neurophysiol. 126, 1847-1868. doi: 10.1016/j.clinph.2014.08.028

Zoladz, J. A., and Pilc, A. (2010). The effect of physical activity on the brain derived neurotrophic factor: from animal to human studies. J. Physiol. Pharmacol. 61, 533-541.

Zoladz, J. A., Pilc, A., Majerczak, J., Grandys, M., Zapart-Bukowska, J., and Duda, K. (2008). Endurance training increases plasma brain-derived neurotrophic factor concentration in young healthy men. J. Physiol. Pharmacol. 59 (Suppl. 7), 119-132.

Conflict of Interest: The authors declare that the research was conducted in the absence of any commercial or financial relationships that could be construed as a potential conflict of interest.

Copyright $\odot 2021$ Nicolini and Nelson. This is an open-access article distributed under the terms of the Creative Commons Attribution License (CC BY). The use, distribution or reproduction in other forums is permitted, provided the original author(s) and the copyright owner(s) are credited and that the original publication in this journal is cited, in accordance with accepted academic practice. No use, distribution or reproduction is permitted which does not comply with these terms. 